\title{
The Nigrostriatal Pathway in the Rat: A Single-Axon Study of the Relationship between Dorsal and Ventral Tier Nigral Neurons and the Striosome/Matrix Striatal Compartments
}

\author{
Lucía Prensa and André Parent \\ Centre de Recherche Université Laval Robert-Giffard, Local F-6500, Beauport, Québec, Canada, G1J 2G3
}

\begin{abstract}
Axons from dorsal/ventral tiers of substantia nigra pars compacta (SNc), ventral tegmental area (VTA), and retrorubral field (RRF) were traced after injecting their cell body with biotinylated dextran amine. Fifty-three single axons were reconstructed from serial sagittal sections with a camera lucida, and $\mu$-opiate receptor immunostaining served to differentiate the striosome/matrix striatal compartments. Most dorsal tier SNc axons terminate within the matrix of the dorsal striatum, but their patterns of arborization vary markedly; some axons innervate one specific matriceal area, whereas others arborize in multiple discontinuous loci. Some dorsal tier SNc axons also project to both striosomes and matrix. Other dorsal tier SNc axons, as well as VTA axons, innervate the ventral striatum and send collaterals to striosomes lying ventrally in the dorsal striatum or to the ventral sector of the subcallosal streak (SS). Ventral tier SNc axons arborize principally in striosomes, but
\end{abstract}

some ramify in both compartments or in striosomes and the SS. Ventral tier neurons that form deep clusters in substantia nigra pars reticulata innervate principally the matrix and the SS. The amygdala and ventral pallidum receive secondary collaterals from striatal axons of dorsal/ventral tier neurons or RRF neurons. The subthalamic nucleus receives collaterals from striatal axons of SNc clustered neurons, whereas the globus pallidus gets collaterals from striatal axons of dorsal/ventral tier SNc neurons. These findings reveal that the nigrostriatal pathway is composed of several neuronal subsystems, each endowed with a widely distributed axonal arborization that allows them to exert a multifaceted influence on striatal and/or extrastriatal structures.

Key words: basal ganglia; substantia nigra; ventral tegmental area; retrorubral field; striatal compartments; nigrostriatal projection; single-cell labeling
The nigrostriatal projection system exerts on the striatum a profound influence that affects both motor and motivational aspects of behavior (Gerfen and Wilson, 1996). This projection is part of a larger mesotelencephalic system that originates from dopaminergic (DA) neurons scattered in the retrorubral field (RRF), substantia nigra pars compacta ( $\mathrm{SNc}$ ), and ventral tegmental area (VTA), corresponding to groups A8, A9, and A10, respectively, of Dahlström and Fuxe (1964) [see also Björklund and Lindvall (1984)]. Neurons of A9 and A8 groups contribute to the nigrostriatal system, whereas those of the A10 supply the mesolimbocortical system, which innervates structures such as the amygdala, septum, olfactory tubercle, and prefrontal/anterior cingulate cortices (Berger et al., 1974; Lindvall et al., 1977; Fallon and Moore, 1978; Fallon and Loughlin, 1985, 1987; Gerfen et al., 1987b).

The striatum is composed of two distinct compartments, the striosomes (or patches) and the surrounding matrix, differing from one another by the expression of neurochemical markers and by input/output connections (Graybiel and Ragsdale, 1978; Herkenham and Pert, 1981; Ragsdale and Graybiel, 1981; Goldman-Rakic, 1982; Gerfen, 1984, 1985; Gerfen et al., 1985; Donoghue and Herkenham, 1986; Graybiel, 1990). The current organizational scheme of the nigrostriatal system holds that neu-

Received Feb. 6, 2001; revised June 22, 2001; accepted June 27, 2001

This research was supported by Grant MT-5781 from the Medical Research Council of Canada. We express our sincere gratitude to Carole Émond, Martin Lévesque, and Cynthia Moore for their technical assistance.

Correspondence should be addressed to Dr. André Parent, Centre de Recherche Université Laval Robert-Giffard, 2601, de la Canardière, Local F-6500, Beauport, Québec, Canada, G1J 2G3. E-mail: Andre.Parent@anm.ulaval.ca.

Copyright (ㄷ) 2001 Society for Neuroscience $0270-6474 / 01 / 217247-14 \$ 15.00 / 0$ rons in the dorsal tier of the SNc project to the matrix, whereas those in its ventral tier target the striosomes (Gerfen et al., 1985, 1987a,b; Jiménez-Castellanos and Graybiel, 1987; Langer and Graybiel, 1989; Gerfen, 1992; Haber and Fudge, 1997; Song and Haber, 2000). However, because of the thinness of these two entities, particularly the dorsal tier, the neuroanatomical methods available up to now lacked the resolution required to precisely determine the areas in which striosome- and matrix-projecting SNc neurons reside (Gerfen, 1984, 1985; Gerfen et al., 1987b).

To circumvent this problem, very small subsets of neurons located in different sectors of the SNc/VTA/RRF complex were microiontophoretically injected under electrophysiological guidance with biotinylated dextran amine. This method ensures detailed tracing of the trajectory and entire arborization of single anterogradely labeled axons (Gauthier et al., 1999). The aim of the present study was thus to compare the patterns of axonal arborization, at both striatal and extrastriatal levels, of neurons located in different sectors of the SNc/VTA/RRF complex, with particular attention paid to the two tiers of the SNc and the striosome/matrix striatal compartments. The striosomes were visualized by the presence of $\mu$-opiate receptor $(\mu \mathrm{R})$ immunoreactivity, as detected on the same sections as those stained for the anterograde tracer. Our study therefore provides the first detailed picture of how single axons from neurons located in either the dorsal or ventral tiers of the $\mathrm{SNc}$ arborize in respect to the striosome/matrix mosaic of the striatum.

\section{MATERIALS AND METHODS}

Preparation of the animals. A total of 45 adult Sprague Dawley rats of both sexes, weighing from 250 to 400 gm, were used in the present study. 
All surgical and animal care procedures adhered to the guidelines for the use and care of experimental animals of the Canadian Council of Animal Care. The Animal Care Committee of Laval University also approved our experimental protocol. The animals were first anesthetized with a solution of $10 \mathrm{cc}$ ketamine hydrochloride $(100 \mathrm{mg} / \mathrm{ml})$ plus $1.5 \mathrm{cc}$ xylazine $(100 \mathrm{mg} / \mathrm{ml})$ administrated intramuscularly $(0.1 \mathrm{cc}$ solution per $100 \mathrm{gm}$ body weight). A local anesthetic (Xylocaine $2 \%$ or Marcaine $0.75 \%$ ) was also administrated in the ears and forehead of the rats before their heads were placed in a stereotaxic apparatus (David Kopf Instruments, Tujunga, CA). The anterograde tracer biotin dextran amine (BDA) (Molecular Probes, Eugene, OR) was injected bilaterally in the dorsal or ventral tier of the SNc, the VTA, or the RRF using the stereotaxic coordinates of the atlas of Paxinos and Watson (1986).

Injection procedures. The microiontophoretic labeling was performed using glass micropipettes (tip diameter 2-3 $\mu \mathrm{m}$ ) filled with a solution of potassium acetate $(0.5 \mathrm{M})$ plus $2 \% \mathrm{BDA}$. The electrodes had impedance of 15-25 $\mathrm{M} \Omega$ and were used to monitor the extracellular activity of midbrain neurons with a recording amplifier (IR-283, NeuroData Instrument, Cygnus Technology, Delaware Water Gap, PA) and a standard oscilloscope. The spontaneous activity of the DA midbrain neurons is characterized by a rather slow single spiking or burst-firing pattern, which is markedly different from the fast and tonic firing of GABAergic neurons of the substantia nigra pars reticulata $(\mathrm{SNr})$ (Grace and Bunney, 1984a,b; Bunney et al., 1991). Because the activity of the DA midbrain neurons is mostly reduced under anesthesia, a small depolarizing current pulse $(0.1 \mathrm{nA})$ was injected through the micropipette at $2 \mathrm{~Hz}$ to detect the presence of silent neurons. When imbalance occurred in the bridge circuitry of the recording amplifier, the micropipette was slowly advanced toward the neuron with the help of a stepping microdriver. The spontaneous activity of the neuron was monitored during 3-4 min to ensure that its firing pattern corresponded to that of an SNc DA neuron and not that of a GABAergic neuron of the SNr. The micropipette was then connected to a high-compliance iontophoresis device (NeuroData), and the tracer was ejected by passing positive current pulses of 300-400 nA ( $1 \mathrm{sec}$ on $/ 1 \mathrm{sec}$ off) for 30-40 min. Each animal received one injection on each side. The injection procedure lasted $\sim 4-5 \mathrm{hr}$. At the end of the surgery the animals were administrated $0.25 \mathrm{cc}$ of a nonsteroidal antiinflammatory analgesic (Anafen $10 \mathrm{mg} / \mathrm{ml}$ ) plus $3 \mathrm{cc}$ of lactated Ringer's solution.

Tracer revelation. After a survival period of 4-7 d, the animals were given an overdose of anesthetic and perfused transcardially with $500 \mathrm{ml}$ saline $(\mathrm{NaCl}, 0.9 \%)$ followed by $1000 \mathrm{ml}$ of a fixative solution containing $4 \%$ paraformaldehyde in $0.1 \mathrm{M}$ phosphate buffer (PB), $\mathrm{pH} 7.4$. After a final wash with $500 \mathrm{ml}$ of $10 \%$ sucrose in $\mathrm{PB}$, the brains were dissected out and sliced along the midline. Each half of the brain was post-fixed in $4 \%$ paraformaldehyde during $1-3 \mathrm{hr}$ and then placed in a cryoprotective solution composed of $30 \%$ sucrose in PB for 1 or $2 \mathrm{~d}$ at $4^{\circ} \mathrm{C}$. They were then sectioned along the sagittal plane at $60 \mu \mathrm{m}$ with a freezing microtome, and the sections were collected serially in $0.1 \mathrm{M} \mathrm{PBS,} \mathrm{pH} \mathrm{7.4.} \mathrm{The}$ sections were placed for $30 \mathrm{~min}$ at room temperature in a solution composed of $10 \%$ hydrogen peroxide $\left(\mathrm{H}_{2} \mathrm{O}_{2} ; 3 \%\right)$ plus $90 \%$ ethanol $(50 \%)$ to eliminate endogenous peroxidase activity. After three rinses in PBS the sections were processed for the visualization of BDA according to the avidin-biotin-peroxidase complex (ABC) histochemical protocol (ABC Standard kit; Vector laboratories, Burlingame, CA). In brief, the sections were incubated overnight at $4^{\circ} \mathrm{C}$ in a solution containing ABC diluted 1:100 in PBS plus 0.3\% Triton X-100. The sections were then rinsed twice in PBS and once in $0.05 \mathrm{M}$ Tris buffer, $\mathrm{pH}$ 7.6. The bound peroxidase was revealed by incubating the sections in a solution containing $0.025 \%$ 3,3'-diaminobenzidine tetrahydrochloride (DAB) (Sigma, St. Louis, MO), $0.3 \%$ nickel-ammonium sulfate, $0.005 \%$ cobalt chloride, and $0.008 \% \mathrm{H}_{2} \mathrm{O}_{2}(30 \%)$ in $0.05 \mathrm{M}$ Tris buffer, $\mathrm{pH} 7.6$, for $10-15 \mathrm{~min}$ at room temperature. The reaction was stopped by a rinse in $0.05 \mathrm{M}$ Tris buffer, $\mathrm{pH} 7.6$, followed by two rinses in PBS.

Immunohistochemistry. To determine the exact location of the injected neurons relative to the surrounding structures, the sections that included the injection site were processed immunohistochemically to reveal the calcium-binding protein calbindin D-28k (CB). The rest of the sections, that is, those that extended from the most lateral aspect of the striatum, laterally, to the level immediately lateral to the injection site, medially, were processed immunohistochemically for the $\mu \mathrm{Rs}$, which is a specific marker of the striosome striatal compartment (Herkenham and Pert, 1981; Wang et al., 1996).

The immunohistochemical protocol used to visualize $\mathrm{CB}$ and $\mu \mathrm{R}$ will now be described briefly. After the tracer revelation, the sections were reincubated for one night at $4^{\circ} \mathrm{C}$ in a solution containing $5 \%$ of either normal horse serum (for CB) or normal goat serum (for $\mu \mathrm{R}$ ), $0.1 \%$ Triton X-100, and the primary antibody. The CB antibody was a mouse monoclonal antibody highly specific for this calcium-binding protein (Sigma; dilution 1:2500). The $\mu \mathrm{R}$ antibody was a polyclonal antibody generated in a rabbit against a synthetic peptide sequence corresponding to amino acids 384-398 predicted from the cloned rat $\mu \mathrm{R} 1$ (DiaSorin, Stillwater, MN; dilution 1:1000). After three rinses of $10 \mathrm{~min}$ each in PBS, the sections were incubated for $1 \mathrm{hr}$ at room temperature in the secondary antibody, which was biotinylated horse $\operatorname{IgG}$ (for $\mathrm{CB}$ ) and biotinylated goat IgG (for $\mu \mathrm{R}$ ). After three more rinses in PBS, the sections were reincubated for $1 \mathrm{hr}$ at room temperature in $2 \%$ avidinbiotin complex (ABC standard kit, Vector Labs) according to the method of Hsu et al. (1981). The bound peroxidase was revealed by placing the sections in a medium containing $0.05 \%$ DAB and $0.018 \% \mathrm{H}_{2} \mathrm{O}_{2}(30 \%)$ in $0.05 \mathrm{M}$ Tris buffer, $\mathrm{pH} 7.6$, at room temperature. The reaction was stopped after $\sim 3-5 \mathrm{~min}$ by a single wash in $0.05 \mathrm{~m}$ Tris buffer, $\mathrm{pH} 7.6$, and several washes in PBS.

A series of sagittal sections from a noninjected rat covering the complete mediolateral extent of the SNc/VTA/RRF complex were processed alternatively for $\mathrm{CB}$ and tyrosine hydroxylase $(\mathrm{TH})$, which is a faithful marker for DA cells at this level. The protocol used to visualize $\mathrm{TH}$ is essentially the same as that described above for CB and $\mu \mathrm{R}$. The TH antibody used in this study was a mouse monoclonal antibody generated against TH isolated and purified from rat PC12 cells (Incstar; dilution 1:1000). All the sections were mounted onto gelatin-coated slides, dehydrated through passages in ascending grades of alcohol, cleared in toluene, and coverslipped with Permount.

Material analysis. The sections immunostained alternatively for $\mathrm{CB}$ and TH were used to obtain a detailed chemical map of the SNc/VTA/RRF complex that would serve to determine in which sector of the complex the BDA-injected neurons were located. This mapping took into account the facts that neurons of the dorsal tier of the SNc express CB and those of the ventral tier do not and that the neuropil of the $\mathrm{SNr}$ is intensely immunoreactive for CB (Gerfen et al., 1987a). Following the superposition of camera lucida mappings of $\mathrm{TH}+$ and $\mathrm{CB}+$ cells, the regions of overlap were found to correspond to the dorsal tier of the SNc, whereas regions of mismatch concur with the ventral tier. The portion of the complex in which $\mathrm{CB}+$ neuropil predominated corresponded to the $\mathrm{SNr}$ (Fig. 1). The latter structure was pierced by a few small oval areas characterized by a relatively poor $\mathrm{CB}+$ neuropil and an abundance of $\mathrm{TH}+$ neurons that were more densely packed than elsewhere in the ventral tier of the SNc (Fig. $1 D, E$ ).

The TH-rich VTA and RRF regions were found to harbor numerous $\mathrm{CB}+$ cells, confirming that the DA neurons in these two groups also express CB (Gerfen et al., 1987a). The SNc is by far the most abundant and widely distributed DA cell population of the midbrain. As seen on sagittal plane, the A9 DA cell group occupies the entire SNc, including some sectors that impinge deeply on the most caudolateral portion of the SNr. It is continuous with the VTA rostromedially and the RRF caudolaterally. The DA neurons of the dorsal tier of the SNc, which express CB and have dendrites preferentially oriented along the mediolateral axis (Fallon et al., 1978; Gerfen et al., 1987a), abound preferentially in the rostral and dorsal sector of the SNc (Fig. 1). However, a large number of A9 DA cells are scattered ventrocaudally in a sector referred to as the ventral tier of the SNc (Fig. 1); these neurons are devoid of $\mathrm{CB}$ and have dendrites oriented dorsoventrally (Fallon et al., 1978; Gerfen et al., 1987a). In the rostral portion of the SNc, most neurons of the ventral tier are confined to the portion of the SNc located outside (or dorsal to) the SNr. More caudally, the ventral tier DA neurons progressively invade the $\mathrm{SNr}$, where they are surrounded by the $\mathrm{CB}+$ neuropil formed by the striatonigral fibers. Finally, the most caudally located DA neurons of the ventral tier of the SNc form typical cell clusters deeply embedded in the SNr (Fig. 1). These clusters were easily recognizable because they formed typical oval sectors in which the $\mathrm{CB}+$ neuropil was weak in comparison to that of the surrounding $\mathrm{SNr}$ (Fig. 1D,E). Thus, on the basis of the chemical map of the SNc/VTA/RRF complex drawn in the present study, the BDA-labeled neurons will be grouped according to their location in the (1) dorsal tier of the SNc, (2) ventral tier of the SNc, outside the SNr, (3) ventral tier of the SNc, within the $\mathrm{SNr}$, (4) clusters of ventral tier SNc cells deeply embedded in the $\mathrm{SNr}$, (5) VTA, and (6) RRF.

After precise mapping of injection sites and labeled neurons, the remaining sections were examined with the help of a $10 \times$ objective to determine the presence of labeled axons. The terminal fields of each axon within the striatum were analyzed carefully, often with use of a $40 \times$ 


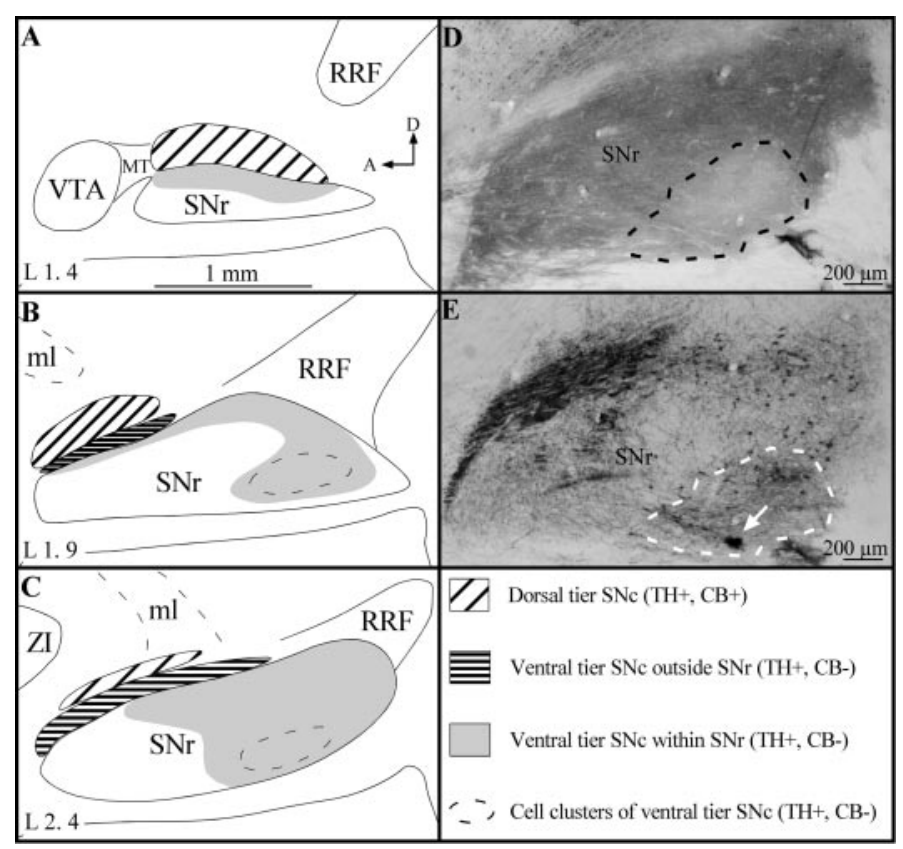

Figure 1. $A-C$, Drawings of the localization and extent of the dorsal and ventral tiers of the A9 dopaminergic cell group on three sagittal sections of the SNc/VTA/RRF complex. The drawings are set out in a mediolateral order, and the laterality $(L)$ of each section, according to the atlas of Paxinos and Watson (1986), is indicated in the bottom left. The different regions of this complex are identified by various hatched and gray areas, the significance of which is explained in the bottom right. D, E, Low-power photomicrographs of two adjacent parasagittal sections of the substantia nigra stained for $\mathrm{CB}(D)$ and $\mathrm{TH}(E)$, respectively. It shows one of the typical SNr oval sectors (dashed line), which is characterized by a CB-poor neuropil and clustered $\mathrm{TH}+$ neurons. The mediolateral level corresponds approximately to that of the drawing in $B$, and the arrow in $E$ points to a small BDA injection site. $A$, Anterior; $D$, dorsal; $M T$, Medial terminal nucleus of the accessory optic tract; $m l$, medial lemniscus. Definitions of abbreviations in this and other legends apply to all figures.

objective, to determine the exact relationship between the axonal arborization patterns and the striosomes/matrix compartmentalization. The axonal terminal fields were also mapped at low magnification, and their exact position was documented in relation to the corresponding planes in the stereotaxic atlas of Paxinos and Watson (1986).

Technical limitations and potential interpretation problems. The present study did not aim at specifically labeling neurons with electrophysiological properties that had been characterized previously in detail. This type of dual information can be obtained with the juxtacellular labeling procedure developed by Pinault (1996) but not with the method that was used here. In the present study, the electrophysiological approach was used essentially as a guiding tool to help us differentiate between $\mathrm{SNc}$ and $\mathrm{SNr}$ neurons, the firing patterns of which differ markedly, as indicated above. This approach was very useful, particularly when attempts were made to localize clusters of SNc neurons deeply embedded within the $\mathrm{SNr}$. However, the confirmation that the injected neurons were indeed located within such cell clusters could only be obtained after the labeling procedure. In that case, only neurons that lay within the typical oval sectors that displayed a poor CB immunostaining were considered to belong to the "ventral tier cell clusters" subdivision. The labeled neurons located in the vicinity of these CB-poor oval sectors were considered to belong to the "ventral tier within SNr" subdivision (see above). No specific functional significance was attributed to these admittedly tenuous subdivisions of the SNc. This partitioning was essentially based on topological criteria and aimed at facilitating the description of the material.

No attempt was made to define the chemical nature of the injected neurons in this study. Hence, although all neurons with axons that have been traced occurred in nigral sectors that contained numerous dopaminergic cells, it is impossible to conclude that they were themselves dopaminergic. This problem is particularly acute in the case of labeled neurons that were deeply embedded in the SNr, where the SNc dopaminergic neurons are known to be closely surrounded by GABAergic $\mathrm{SNr}$ neurons. We fully acknowledge the possibility that some of the neurons described in this study, principally those with an axon that arborized profusely at both thalamic and brainstem levels (see below), might be GABAergic SNr neurons instead of dopaminergic SNc neurons. These neurons were retained in the present sample only because they also had axon collaterals that arborized in the striatum, which is, by definition, the morphological trait that defines all nigrostriatal neurons. We emphasize the fact that the aim of the present study was to investigate the axonal branching pattern of as many nigrostriatal neurons as possible, regardless of their topographical location and neurotransmitter phenotype.

In this study, most of our efforts have been devoted to the characterization of neurons of the dorsal and ventral tiers of the SNc in relation to the striosome/matrix striatal compartmentalization. Consequently, the VTA and RRF were sampled much less extensively than the SNc. For example, only the dorsalmost aspect of the VTA was surveyed in this study, a limitation that may explain the absence of VTA neurons projecting to the cerebral cortex in our sample. The labeled axons from the VTA and RRF were retained here nevertheless because we thought it useful to compare their pattern of striosome/matrix striatal arborization with that of the SNc nigrostriatal neurons. However, we are fully aware that a much more detailed investigation of the VTA is needed for a general picture of the organization of the mesocortical projection system to emerge.

\section{RESULTS}

\section{General labeling features}

A total of 27 injection sites located in different sectors of the $\mathrm{SNc} / \mathrm{VTA} / \mathrm{RRF}$ complex were analyzed in the present study. The injection protocol used here produced very small injection sites, most of which had a dense core of BDA precipitate surrounded by a few (one to five) neurons that were labeled in a Golgi-like manner. Some of these neurons were located rather far from the injection site, and their somatodendritic domain was particularly well delineated. Intensely labeled axons exited either from the core of the injection site or from individually labeled neurons located peripherally. In the latter case, the axons emerged from the perikarya or a primary dendrite. These axons could easily be followed individually throughout each section and they were thus reconstructed entirely along the sagittal plane with a camera lucida. A total of 53 axons that emerged from the dorsal or ventral tiers of the SNc, the VTA, or the RRF were entirely reconstructed in the present study.

\section{Dorsal tier of the SNc}

Nineteen axons emerging from different sectors of the dorsal tier of the SNc were entirely reconstructed. On the basis of their pattern of arborization at the striatal level, these axons were subdivided into three types: (1) axons innervating principally the matrix compartment; (2) axons innervating densely both the striosome and matrix compartments; and (3) axons projecting to the ventrolateral aspect of the striatum, an area that corresponds to fundus striati of Paxinos and Watson (1986). The fundus striati is not considered here as a distinct striatal compartment, and we do not attribute to this entity any particular functional property that would be different from the rest of the ventral striatum. This term was used only to facilitate the description of the location of the labeled profiles in accordance with the atlas of Paxinos and Watson (1986).

\section{Type 1 axons}

Type 1 axons were the most abundant type of dorsal tier axons $(n=12)$. Most of them headed directly to the striatum (Fig. $2 A, B)$, but some ran medially throughout the VTA and showed elongated varicosities and sporadic terminal boutons before turning rostrally toward the striatum. All axons passed above the 
Figure 2. A, Camera lucida drawing of a dorsal tier type $1 \mathrm{SNc}$ axon, as viewed in the sagittal plane. The compartmental organization of its terminal field is illustrated in $D$. B, Photomicrograph illustrating the BDA deposit in the dorsal tier of SNc. Note the $\mathrm{CB}+$ cell bodies scattered in the dorsal tier and the $\mathrm{CB}+$ neuropil that characterizes $\mathrm{SNr}$ but is absent in SNc. The arrow points to the neuron the axon of which is drawn in $A$. $C$, Photomicrograph showing part of the terminal arborization in the matrix of the axon drawn in $E$. The asterisk indicates one $\mu \mathrm{R}+$ striosome. $D-F$, Striatal branching of three different type 1 axons. The shaded areas in the caudateputamen indicate the $\mu \mathrm{R}+$ striosomes and subcallosal streak. $a c$, Anterior commissure; $C C$, corpus callosum; $C P u$, caudate-putamen; $L V$, lateral ventricle; $i c$, internal capsule; $O T$, optic tract; $S S$, subcallosal streak; $T h$, thalamus. Definitions of abbreviations apply to all figures.

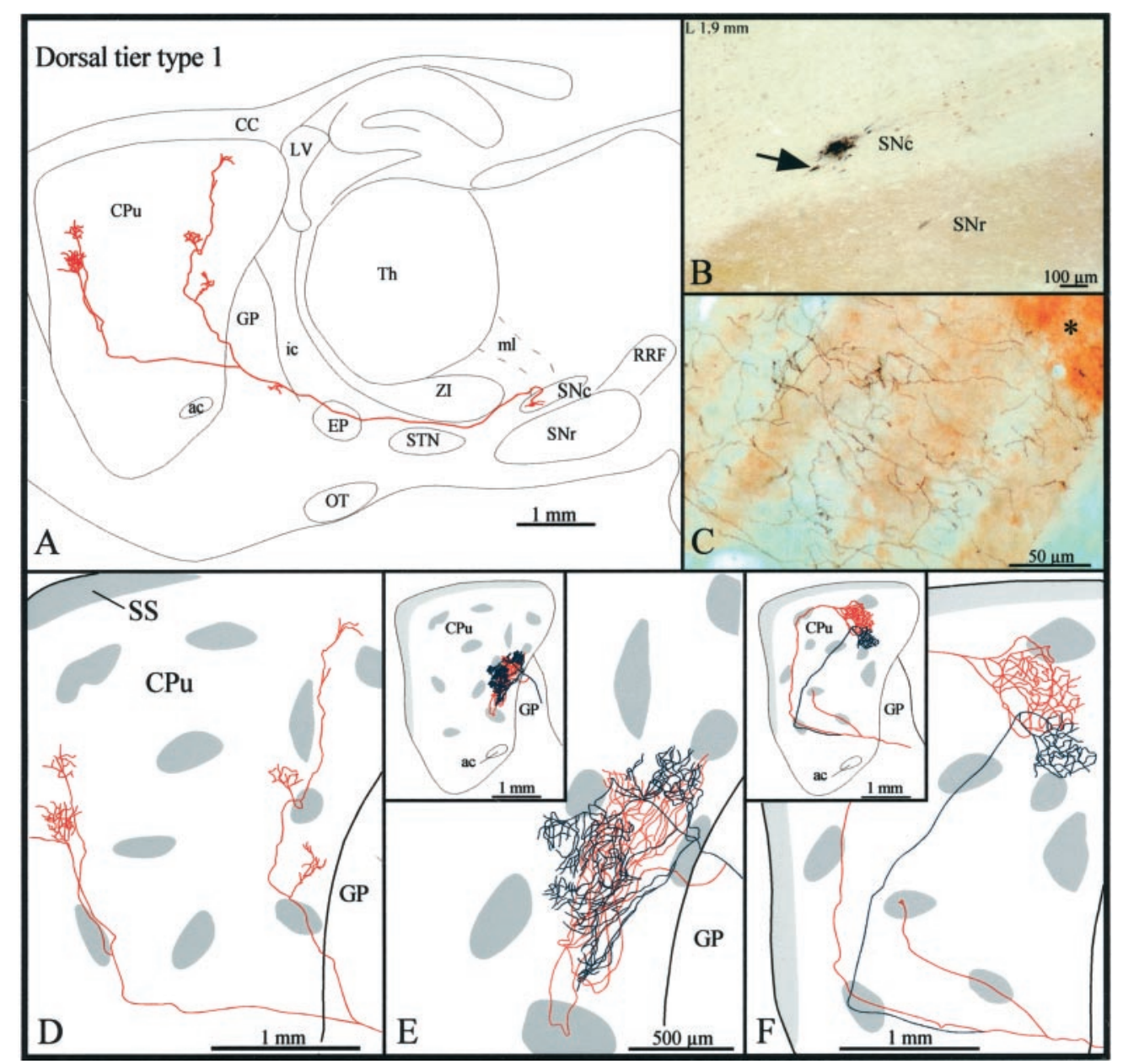

subthalamic nucleus (STN) and below the ventral edge of the zona incerta (ZI) en route to the striatum (Fig. 2A). Some axons displayed a few terminal boutons and/or elongated varicosities, reminiscent of boutons en passage, as they traversed the entopeduncular nucleus (EP), and most emitted one or two short and varicose collaterals in the caudal third of the globus pallidus (GP), before penetrating the striatum (Fig. 2A).

The majority of type 1 axons bifurcated in either the rostral portion of the GP, very close to the striatal boundary, or as soon as they penetrated the striatum (Fig. $2 A, D-F$ ). In most cases, the two major axonal branches coursed for a rather long distance within the striatum and emitted two to five short collaterals along their way (Fig. 2A,D). These collaterals, as well as the main axonal branches, often traversed striosomes but did not exhibit varicosities or any other terminal features as they ran through the striosomal compartment (Fig. 2D,F). The collaterals coursed for a rather short distance before breaking out into several thinner and slightly varicose fibers that formed rather discrete terminal fields in different sectors of the extrastriosomal matrix (Fig. $2 A, D)$. Occasionally, the two main branches of one axon, after following different or similar trajectories within the striatum, arborized either densely or more weakly within the same discrete matriceal area of the striatum (Fig. 2C,E,F).

Four other type 1 axons emitted a very thin collateral that targeted either one striosome located in the rostral half of the striatum (Fig. $2 F$ ) or, less commonly, the subcallosal streak. In the latter case, the collateral coursed ventrolaterally throughout the GP and emitted several short collaterals and terminal boutons in the ventral pallidum, before penetrating the striatum. The density of the terminal arborization of these collaterals within the striosomes or the subcallosal streak was very low in all cases.

\section{Type 2 axons}

Type 2 axons $(n=3)$ emerged from cell bodies located in the most medial aspect of the dorsal tier of the SNc (Fig. 3A, inset). Before leaving the substantia nigra, this particular axon emitted two local collaterals that branched into several thin and varicose collaterals scattered along the ventral sector of the $\mathrm{SNc}$ and in the most dorsal aspect of the $\mathrm{SNr}$ (Fig. $3 A, D$ ). The axon ascended below the ZI, and after emitting a short and thin collateral in the subincertal nucleus, it bifurcated into two main branches that penetrated the EP by coursing parallel to one another (Fig. $3 A$ ). The more medially located branch (illustrated in red in Fig. 3) emitted three collaterals that arborized within the medial aspect of the EP and another collateral that reached the most ventral aspect of the reticular thalamic nucleus (Rt). The more laterally located branch (illustrated in blue in Fig. 3) provided only one short and poorly ramified collateral in the lateral aspect of the EP and in the most rostral sector of the ZI. The terminal fibers in the EP exhibited numerous round varicosities reminiscent of boutons terminaux. Both axonal branches followed a rather straight course through the GP, and only the lateral branch emitted one short collateral exhibiting large varicosities and boutons terminaux in the caudal sector of this nucleus.

The two branches penetrated the striatum by its dorsal half. The one in red headed toward the lateral aspect of the striatum 


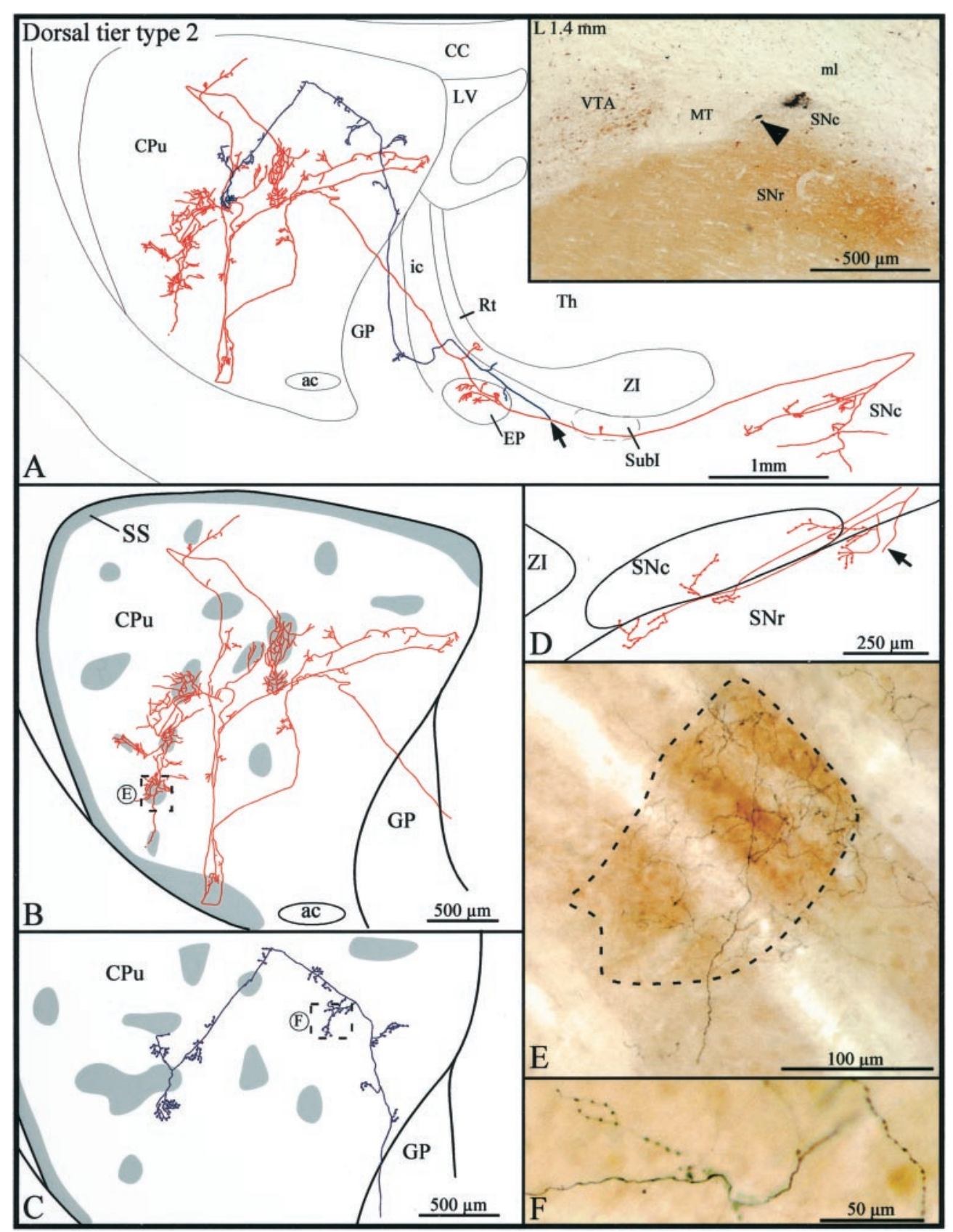

Figure 3. A, Camera lucida drawing of a dorsal tier type $2 \mathrm{SNc}$ axon, the parent cell body of which is pointed out by the arrowhead in the inset. This neuron is located beside a very small injection site in the medial aspect of the dorsal tier of the SNc. The arrow in the drawing indicates the level at which the main axon bifurcates, and the two axonal branches are represented in red and blue, respectively. $B, C$, High-power views of the striatal arborization of each axonal branch. The shaded areas indicate the $\mu \mathrm{R}+$ striosomes and subcallosal streak. $D$, Camera lucida drawing showing the distribution of the local axonal collaterals in the substantia nigra. The arrow points to the main axon. $E, F$, Photographic enlargements of the terminal arborizations of each axonal branch at the level indicated by the dotted rectangles in $B$ and $C$. SubI, Subincertal nucleus. Definition applies to all figures. and, along its way, emitted several short and varicose collaterals that remained confined to the matrix. It reached the most ventral aspect of the striatum, where it arborized within the $\mu \mathrm{R}+$ subcallosal streak and adjacent matrix area (Fig. $3 B$ ). As the branch exited the subcallosal streak it bifurcated, and the two new branches ascended in the central portion of the striatum where they broke out into multitudinous thinner and slightly varicose fibers. Some of these fibers penetrated striosomes and others remained in the matrix, but the collaterals were notably more highly branched in striosomes than matrix (Fig. 3B,E). A total of six striosomes were densely innervated by the fibers that derived from this single axonal branch (Fig. $3 B$, red). In comparison to this widely distributed branch, the other (blue) axonal branch remained rather centrally located, traveled almost exclusively in the matrix, and emitted numerous short collaterals, which exhibited numerous round varicosities reminiscent of boutons en pas- sant (Fig. 3C,F). It traversed two striosomes along its trajectory but did not exhibit any peculiar feature as it ran through them (Fig. 3C).

The other type 2 axons were less prof usely arborized at striatal levels. They both penetrated the striatum through its ventral half and gave rise to two branches that headed in parallel toward the rostral sector of the striatum. At this level, one branch arborized exclusively in the matrix, whereas the other innervated densely a few striosomes and, much more diffusely, the surrounding matrix area. One of these two type 2 axons had local collaterals that arborized in the dorsal and ventral tiers of the $\mathrm{SNc}$ as well as in the dorsal aspect of the SNr.

\section{Type 3 axons}

These axons $(n=4)$ emerged from the same rostral sector of the dorsal tier of the SNc that gave rise to type 1 axons (Fig. 2B). 


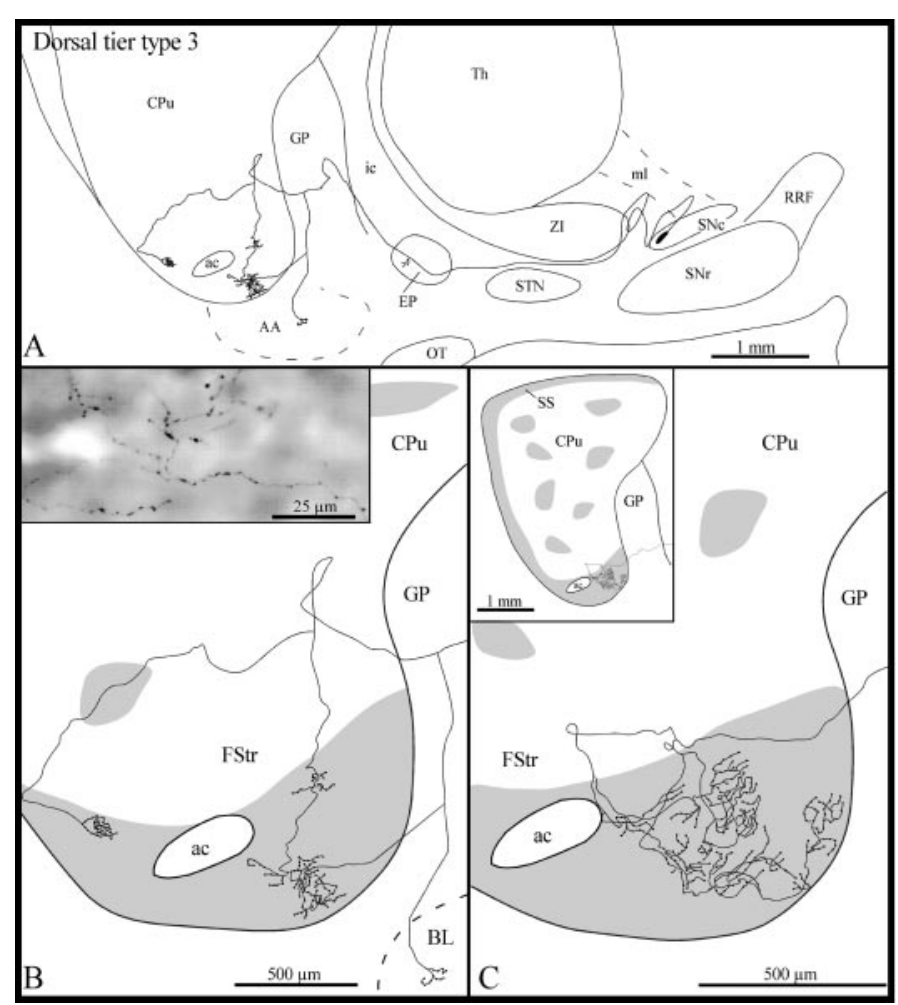

Figure 4. A, Camera lucida drawing of a dorsal tier type $3 \mathrm{SNc}$ axon, as viewed in the sagittal plane. $B$, High-power view of the terminal arborization of this axon in the fundus striati (FStr). The inset in $B$ is a photographic enlargement of some varicose terminal collaterals of this axon in the fundus striati. $C$, High-power view of the terminal arborization in the fundus striati of another dorsal tier type 3 axon. The inset in $C$ provides an overall view of the arborization of this axon at the striatal level. The gray areas in $B$ and $C$ represent $\mu \mathrm{R}+$ sectors of the striatum. $A A$, Amygdala; $B L$, basolateral amygdaloid nucleus. Definitions apply to all figures.

Following a highly convoluted initial course in the SNc, the type 3 axons ascended medially within the lateral hypothalamic area (Fig. $4 A$ ). All the axons emitted a few short and varicose collaterals in the EP, and three of them also gave off one thin and varicose collateral in the rostral third of the GP (Fig. 4A). This collateral coursed ventrolaterally throughout the GP and penetrated the fundus striati. In one case, however, this thin collateral bifurcated in the ventral region of the GP; one branch coursed ventrolaterally to reach the basolateral nucleus of the amygdala, whereas the other penetrated the fundus striati (Fig. 4A, $B$ ).

In three cases, the axons entered the ventral third of the striatum and descended along the striatopallidal boundary before reaching the fundus striati (Fig. 4A,B). Only one axon penetrated directly the fundus striati (Fig. $4 C$ ). The axons coursed laterally within the fundus striati and emitted several collaterals that arborized close to the parent axon into several thin fibers that formed a few clusters of various sizes scattered along the mediolateral extension of the fundus striati (Fig. $4 B, C$ ). These terminal fibers were markedly varicose (Fig. $4 B$, inset). The terminal fields of two of these axons covered a rather wide mediolateral sector of the fundus striati (720 and $840 \mu \mathrm{m}$, respectively). One of the axons provided a thin collateral that reached the most ventral aspect of the subcallosal streak, almost at its junction with the fundus striati. After innervating the most rostroventral aspect of the fundus striati, another axon emitted three collaterals that

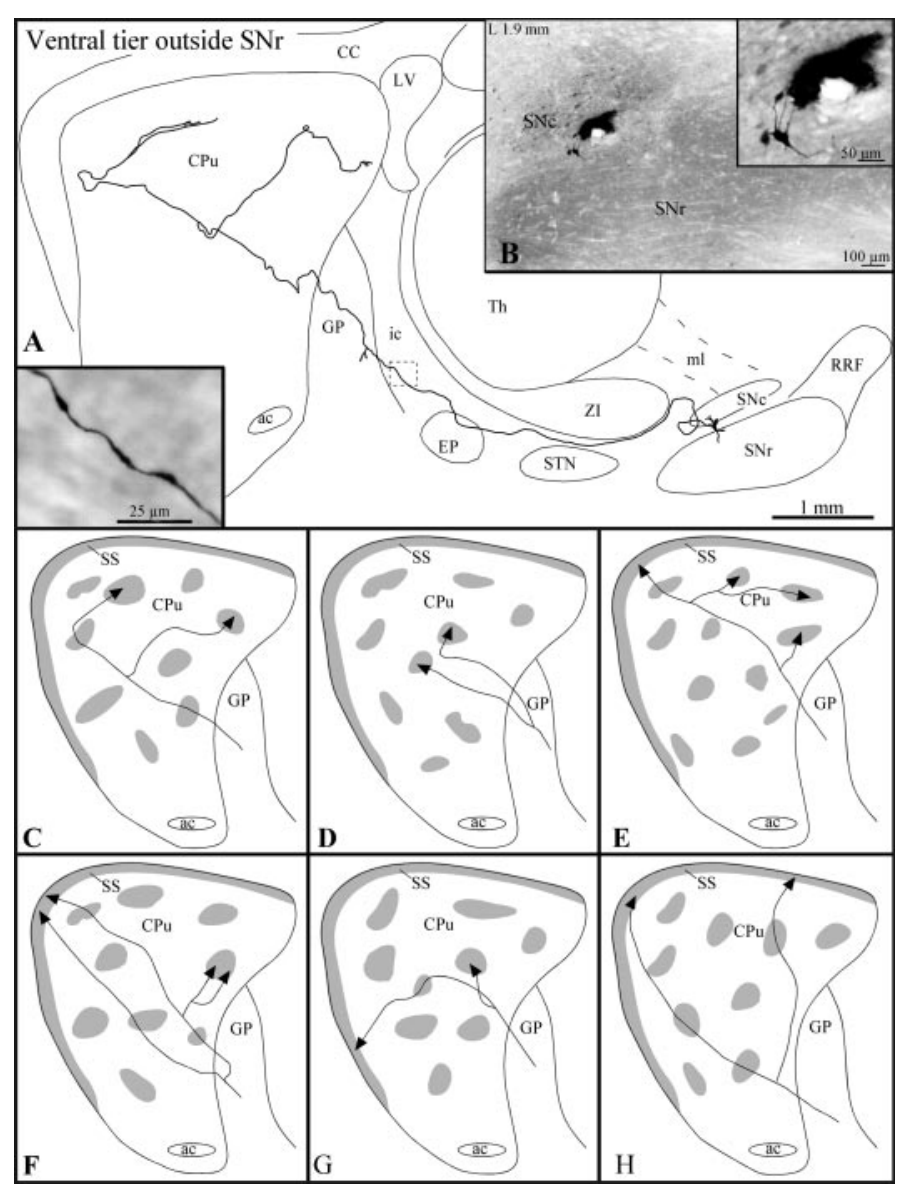

Figure 5. A, Camera lucida representation of a ventral tier SNc axon, the neuron of which is located outside the $\mathrm{SNr}$, as viewed in the sagittal plane. The striatal arborization of this axon is illustrated in $C$, with gray areas representing $\mu \mathrm{R}+$ sectors. The inset in $A$ illustrates the varicose aspect of this axon at the level indicated by the dashed square in the drawing. $B$, Photomicrograph illustrating the BDA deposit in the ventral tier outside the $\mathrm{SNr}$ and the neuron the axon of which is drawn in $A$. Note that the labeled neuron, shown at a higher power view in the inset in $B$, is located just above the dorsal boundary of the $\mathrm{SNr}$ and displays dorsoventrally oriented dendrites. $C-H$, Striatal arborization of six axons of ventral tier neurons located outside the SNr.

coursed ventrally to reach the ventral pallidum, where they arborized in several thinner and varicose fibers that had the same beaded appearance as that of the axonal segments innervating the fundus striati.

\section{Ventral tier of the SNc}

A total of 23 axons originating from different sectors of the ventral tier of the SNc were reconstructed. These neurons were subdivided into three groups on the basis of the location of their parent cell bodies: (1) neurons lying outside (dorsal to) the boundaries of the $\mathrm{SNr}$ (Fig. $5 B$ ), (2) neurons scattered within the boundaries of the $\mathrm{SNr}$ (Fig. $6 A$, inset), and (3) neurons forming clusters located deeply within the $\mathrm{SNr}$ (Fig. $7 B$ ).

\section{Ventral tier neurons lying outside the $\mathrm{SNr}$}

According to their pattern of arborization at the striatal level, the axons $(n=12)$ of these neurons were grouped into three types: (1) axons innervating principally the striosomes $(n=5),(2)$ axons innervating striosomes and the subcallosal streak $(n=4)$, and (3) axons innervating exclusively the subcallosal streak $(n=3)$. 


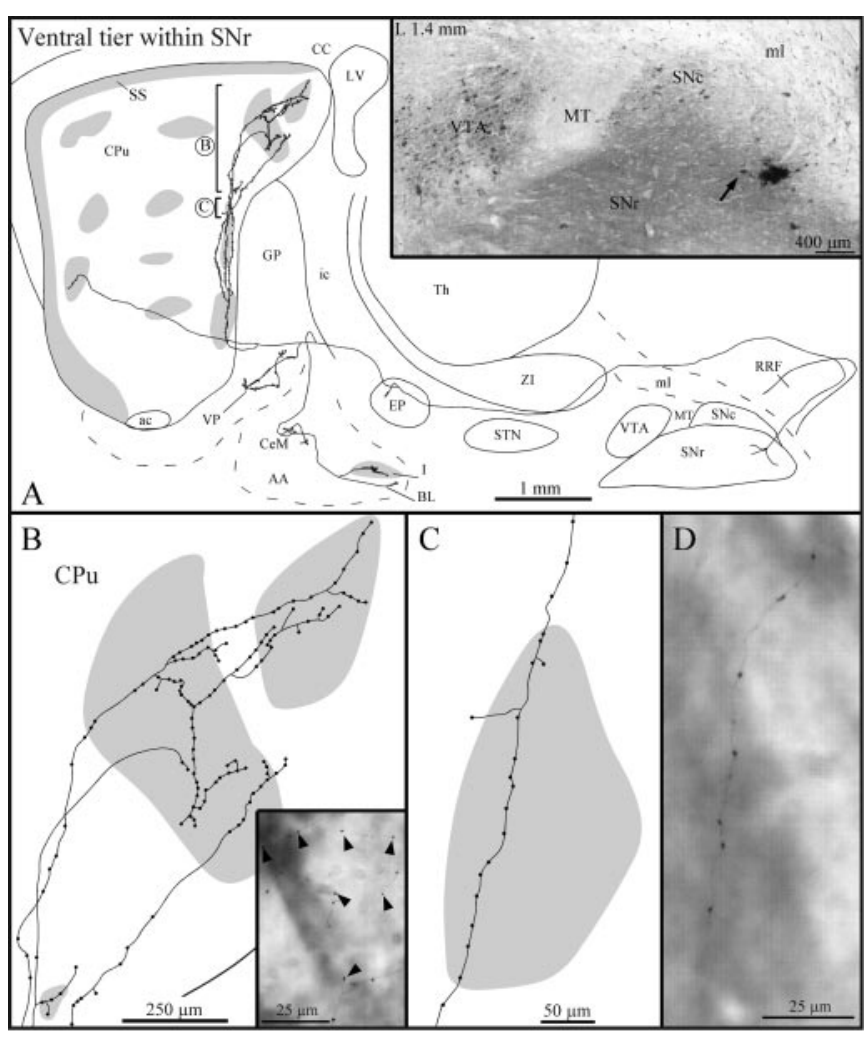

Figure 6. A, Camera lucida drawing of a ventral tier $\mathrm{SNc}$ axon the neuron of which is located within the $\mathrm{SNr}$ (see arrow in inset). The striatal arborization of this axon is shown in $A$, with gray zones representing $\mu \mathrm{R}+$ sectors. $B$, High-power view of the striatal terminal arborization of the axon at the level indicated by the circled $B$ in $A$. The inset in $B$ is a photographic enlargement of some terminal collaterals, which are highly varicose and spread over a striosome and the surrounding matrix (arrowheads). $C$, High-power view of one of the axonal collaterals as it traverses a striosome at the level indicated by the circled $C$ in $A$. The collateral exhibits axonal varicosities and two isolated terminal boutons at the tip of fine stalks. Note that one of the stalks traversed striosomal boundaries so that the bouton lies in the adjacent matrix. $D$, High-magnification view of part of an axon collateral that courses through the striatum before it reaches its termination site. This fiber is extremely thin and displays numerous round varicosities. $C e M$, Central amygdaloid nucleus, medial division; $I$, intercalated amygdaloid nuclei; $V P$, ventral pallidum. Definitions of abbreviations apply to all figures.

Type 1 and 2 axons exhibited elongated varicosities along their entire course from the SNc to the striatum (Fig. $5 A$, inset). They all ascended above the STN and traversed the EP without emitting any collateral (Fig. $5 A$ ). All type 1 axons and one of the type 2 axons provided a short and varicose collateral in the caudal part of the GP (Fig. 5A). The type 1 and 2 axons entered the striatum by its dorsal half. Type 3 axons made a detour through the rostral sector of the RRF before ascending toward the striatum. Two type 3 axons emitted an ascending collateral that penetrated the thalamus and arborized in the ventral aspect of the Rt or continued its route up the ventrolateral nucleus, where it became too thin to be traced any further. All type 3 axons emitted one short and varicose collateral in the EP as they coursed toward the striatum.

Type 1 axons innervated not more than one or two striosomes (Fig. 5C,D). Three of these axons did not branch until they reached their striosomal target, whereas the other two bifurcated in either the GP or the striatum, each branch innervating a different striosome (Fig. $5 C, D$ ). The striosomal terminal fields consisted of a few round varicosities to several thin and varicose fibers, some of which provided a few terminal boutons in the surrounding matrix.

Type 2 axons traversed the striatum along its rostrocaudal axis and penetrated the subcallosal streak, where they exhibited a few round varicosities or terminal boutons (Fig. $5 E-G$ ). Along their striatal trajectory, these axons emitted between one and four thin collaterals that penetrated different striosomes (Fig. $5 E-G$ ). In some cases the collaterals bifurcated before entering the striosome, and the two branches reached either the same or two nearby striosomes (Fig. $5 E, F$ ). The terminal portion of the collaterals often exhibited a few round varicosities reminiscent of terminal boutons, whereas other collaterals arborized into a few thin and varicose fibers. Most of these fibers remained within the striosomal boundaries, but others provided one or two terminal boutons in the nearby matrix. One of the axons emitted one collateral that did not target any striosome but provided a few terminal boutons to the dorsolateral matrix.

Type 3 axons targeted exclusively the dorsal aspect of the subcallosal streak. In cases of axons that bifurcated before reaching their target, the two axonal branches reached sectors of the subcallosal streak that were widely separated along the rostrocaudal or mediolateral planes (Fig. $5 H$ ). Their terminal fields consisted mostly of a few extremely thin and varicose fibers that did not course far in the subcallosal streak.

\section{Ventral tier neurons lying within the $\mathrm{SNr}$}

All seven axons of this group innervated very densely a specific set of striosomes and much less profusely the surrounding matrix (Fig. 6). After a long detour through the RRF (Fig. 6A), the axons turned rostrally, ran above the STN, and emitted a short and varicose collateral in the EP. They then traversed the ventral third of the GP, where they emitted two collaterals: a short and poorly ramified one that arborized in the ventral pallidum, and a longer and more ramified one that reached the amygdala. The latter collateral branched again in the amygdala and provided thinner collaterals that targeted the central medial nucleus, one of the $\mu \mathrm{R}+$ intercalated masses and the basolateral nucleus (Fig. $6 A$ ). The collaterals that innervated the intercalated mass and the ventral pallidum exhibited numerous prominent varicosities, whereas those that arborized in the central medial and basolateral amygdaloid nuclei were rather smooth and yielded only a few terminal boutons at their extremities.

Just before penetrating the striatum, the main axon bifurcated, giving rise to a branch that coursed dorsomedially along the striatopallidal boundary and another that headed rostrally (Fig. $6 A$ ). The dorsally coursing fiber emitted two collaterals that ran parallel to their parent branch. These three fibers were extremely thin and exhibited numerous large varicosities intermingled with smaller ones (Fig. $6 B-D$ ). They traversed several striosomes and provided a few pedunculated terminal boutons in some of them (Fig. 6C). Some fibers emitted one thin and long stalk that traversed the striosomal boundary and yielded a terminal bouton in the adjacent matrix (Fig. 6C). The three fibers entered the same striosomes in the dorsocaudal sector of the striatum, where they branched into several varicose fibers (Fig. 6A,B). Some of these fibers arborized rather poorly in the surrounding matrix (Fig. 6B). The rostrally coursing branch was notably less varicose and penetrated one striosome located at the most rostral aspect of the striatum (Fig. 6A). It did not ramify further in this striosome, but its terminal segment displayed a few varicosities. 
Figure 7. A, Camera lucida drawing of a ventral tier SNc axon the neuron of which lies in a typical CB-poor oval sector (dashed line) in the $\mathrm{SNr}$, as viewed in the sagittal plane. The axon bifurcates within the $\mathrm{SNr}$, and the two main axonal branches are depicted in blue and red, respectively. $B$, Photomicrograph of the BDA deposit in the ventral portion of the $\mathrm{SNr}$ surrounded by the neuron the axon of which is drawn in $A$. The arrowheads point to the initial segment of the axon of this neuron. The inset in $B$ offers a high-power view of the neuron (arrow) and part of its axon (arrowhead). C, High-power view of the terminal arborization of this axon, with gray zones representing $\mu \mathrm{R}+$ striatal sectors. The inset in $C$ is a photographic enlargement of some terminal collaterals lying in the matrix. $D$, Highpower view of the axonal arborizations within the STN, ZI, Rt, ic, and EP. The arrow points to the level at which the blue axonal branch bifurcates. The inset in $D$ is a photographic enlargement of some terminal collaterals in the rostral pole of the STN. DpMe, Deep mesencephalic nucleus; $F r$ 2, frontal cortex, area 2. Definitions apply to all figures.

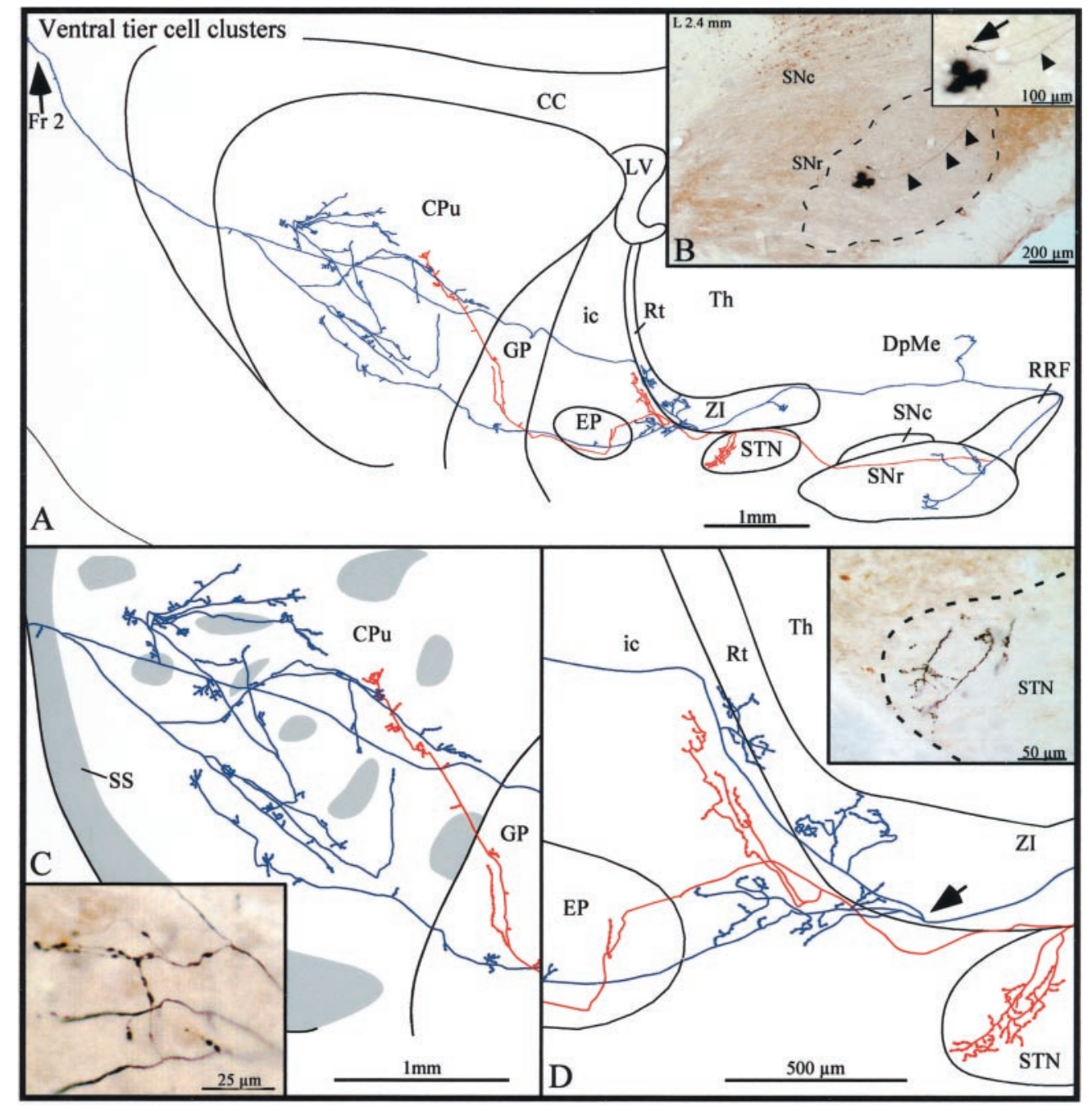

Some axons of this group also provided short collaterals to the subincertal nucleus and ventral sector of the Rt, but did not innervate the amygdala and the ventral pallidum.

\section{Ventral tier neurons forming clusters in the $\mathrm{SNr}$}

The first axon of this highly diversified group $(n=4)$ emitted three local and poorly arborized collaterals exhibiting varicosities and some isolated terminal boutons in the vicinity of the parent cell body and in the dorsocaudal sector of the $\mathrm{SNr}$ (Fig. 7A,B). Just before leaving the $\mathrm{SNr}$, the axon bifurcated into two main axonal branches that reached the striatum through different trajectories; one branch coursed medially (depicted in blue in Fig. 7) and the other traveled laterally (illustrated in red in Fig. 7).

The blue axonal branch made a long detour through the RRF before it headed rostrally toward the striatum. It emitted a collateral that innervated the deep mesencephalic nucleus and another collateral that arborized in the caudal ZI (Fig. 7A). It then subdivided itself into dorsal and ventral branches that both reached the striatum. The dorsal branch arborized rather densely in the ZI and Rt (Fig. $7 A, D$ ), whereas the ventral branch provided several varicose fibers in the area of the internal capsule located between the EP and the ZI and then traversed the EP and the GP, providing one short and varicose collateral in each of these structures (Fig. 7D). At the striatal level, this branch arborized frequently and its terminal field covered a large sector of the striatum, but it remained confined to the matrix compartment (Fig. 7A,C). The terminal arborization consisted of very thin fibers that exhibited round varicosities and formed small clusters scattered throughout a large portion of the striatum (Fig. 7C). This axonal branch gave off a thin collateral that provided three terminal boutons in the subcallosal streak, exited the striatum, and arborized in a pericellular manner in the deep layers of area 2 of the frontal cortex (Fig. $7 A$ ).

The red axonal branch coursed rostrolaterally throughout the dorsal aspect of the SNr and STN (Fig. 7A). It emitted a collateral that arborized in the rostral pole of the STN and another that ramified along the lateral border of the Rt (Fig. $7 A, D$ ). It yielded a varicose and unbranched collateral in both the EP and GP (Fig. $7 C, D)$ and then branched very poorly in the caudal aspect of the striatum, where its fine terminal collaterals were confined to the matrix (Fig. 7C).

The second axon of this group (Fig. 8) emitted one collateral just before leaving the SNr. This collaterals coursed rostrally and bifurcated before reaching the ZI. The two branches penetrated the thalamus and arborized densely in the ventromedial, paracentral, and ventrolateral thalamic nuclei (Fig. 8A,D,E). As the main axon traveled dorsally through the RRF, it emitted a second collateral that ran caudally and innervated densely the pedunculopontine tegmental nucleus (Fig. $8 A, C$ ) and less densely the 


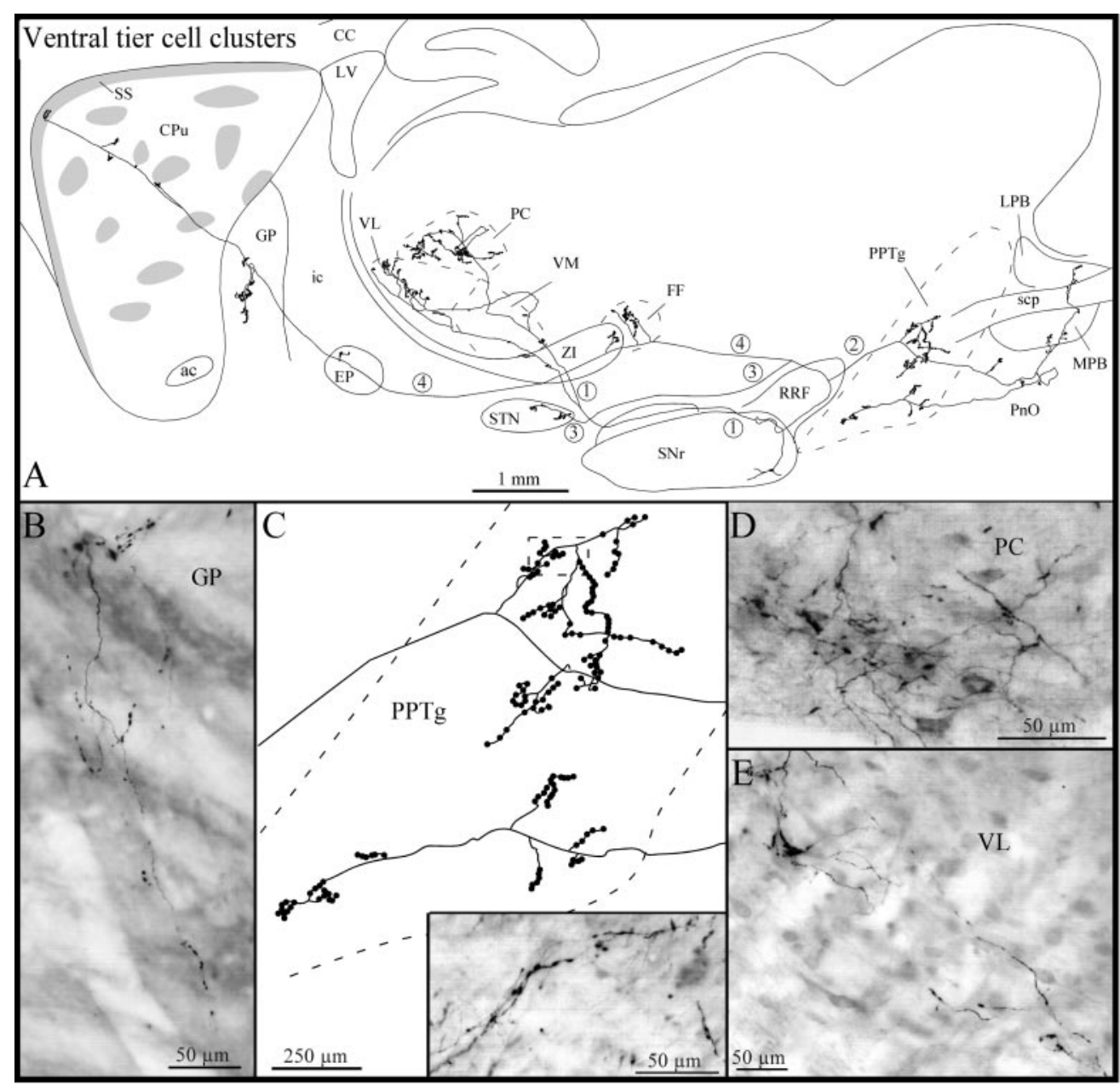

Figure 8. A, Camera lucida drawing of another ventral tier axon the neuron of which lies in a cell cluster located in the $\mathrm{SNr}$, as viewed in the sagittal plane. The main axon (4) and its three main collaterals (1-3) are numbered to facilitate their identification. $B$, Photomicrograph of one axon collateral within the GP giving rise to several pedunculated terminal boutons. $C$, High-power view of the terminal arborization within the pedunculopontine tegmental nucleus (PPTg). The inset in $C$ is a photographic enlargement of some terminal collaterals in the PPTg at the level indicated by the dotted rectangle in the drawing in C.D, E, Photomicrographs of the terminal field within the paracentral thalamic nucleus $(P C)(D)$ and of some axonal collaterals in the ventrolateral thalamic nucleus $(V L)(E) . F F$, Fields of Forel; $L P B$, lateral parabrachial nucleus; $M P B$, medial parabrachial nucleus; $\mathrm{PnO}$, pontine reticular nucleus, oral part; $s c p$, superior cerebellar peduncle; $V M$, ventromedial thalamic nucleus. Definitions of abbreviations apply to all figures. pontine reticular nucleus and the medial and lateral parabrachial nuclei (Fig. 8A). The axon reached the dorsal aspect of the RRF, turned rostrally, and emitted a third collateral that coursed ventrolaterally and targeted the caudal sector of the STN (Fig. 8A). Farther rostrally, the main axon provided short and varicose collaterals to Forel's fields and caudal aspects of ZI (Fig. 8A) and emitted a few classical terminal boutons in the EP and several pedunculated terminal boutons in the GP (Fig. $8 A, B$ ). At the striatal level, the main axon followed a rather straight course and reached the most rostrodorsal sector of the subcallosal streak, where it ramified into a few short and slightly varicose fibers (Fig. $8 A$ ). Along its trajectory, the branch emitted four short collaterals that subdivided into a few terminal fibers exhibiting round varicosities and club-like terminals. The terminal fields of two of these collaterals lay exclusively within the matrix, whereas those from the other two collaterals were located just at the boundary between one striosome and the matrix (Fig. $8 A$ ).

The third axon of this group bifurcated into two main trunks just after departing from the cell body. After a detour in the RRF, the first trunk emitted a collateral that penetrated the thalamus and innervated densely the anteromedial, paracentral, and central medial thalamic nuclei. It also provided a short varicose collateral in the EP and bifurcated just before penetrating the ventral sector of the GP. Both fibers entered the GP and one of them coursed dorsally, providing numerous varicose collaterals that covered a large sector of this nucleus. The other fiber coursed rostrally and, after emitting a short collateral in the GP, entered the striatum.
At the striatal level, the fiber followed a straight course until it penetrated the subcallosal streak, where it exhibited some varicosities at its end. The second main trunk took a direct rostral course and emitted an ascending collateral that innervated the caudal pole of the STN. It ascended rostrally to the EP and emitted several varicose fibers in the area separating the EP and the Rt. The branch then turned and ran backward toward the substantia nigra. It became very poorly stained as it coursed within the RRF and could not be followed up to its terminal site.

The fourth axon of this group displayed a rather convoluted initial course and emitted four local collaterals that ramified profusely in the caudal sector of the SNr. It then coursed rostrally and emitted one collateral that turned caudally and penetrated the rostral pole of the SNr. This collateral gave off a single short branch that ramified poorly in the rostroventral sector of the $\mathrm{SNr}$ and then continued its course up to the caudal aspect of this structure. At this level it arborized into several varicose fibers that were intermingled with those derived from the local axon collaterals. The main axon emitted two other collaterals that innervated the rostral sector of the STN and the rostral pole of the EP. The axon then entered the GP by its ventral aspect and bifurcated. Both branches followed an ascending course throughout the GP and provided numerous collaterals that covered a large portion of this nucleus. Some of these collaterals penetrated the striatum and innervated $\mu \mathrm{R}+$ striatal areas that lay at the striatopallidal junction. 


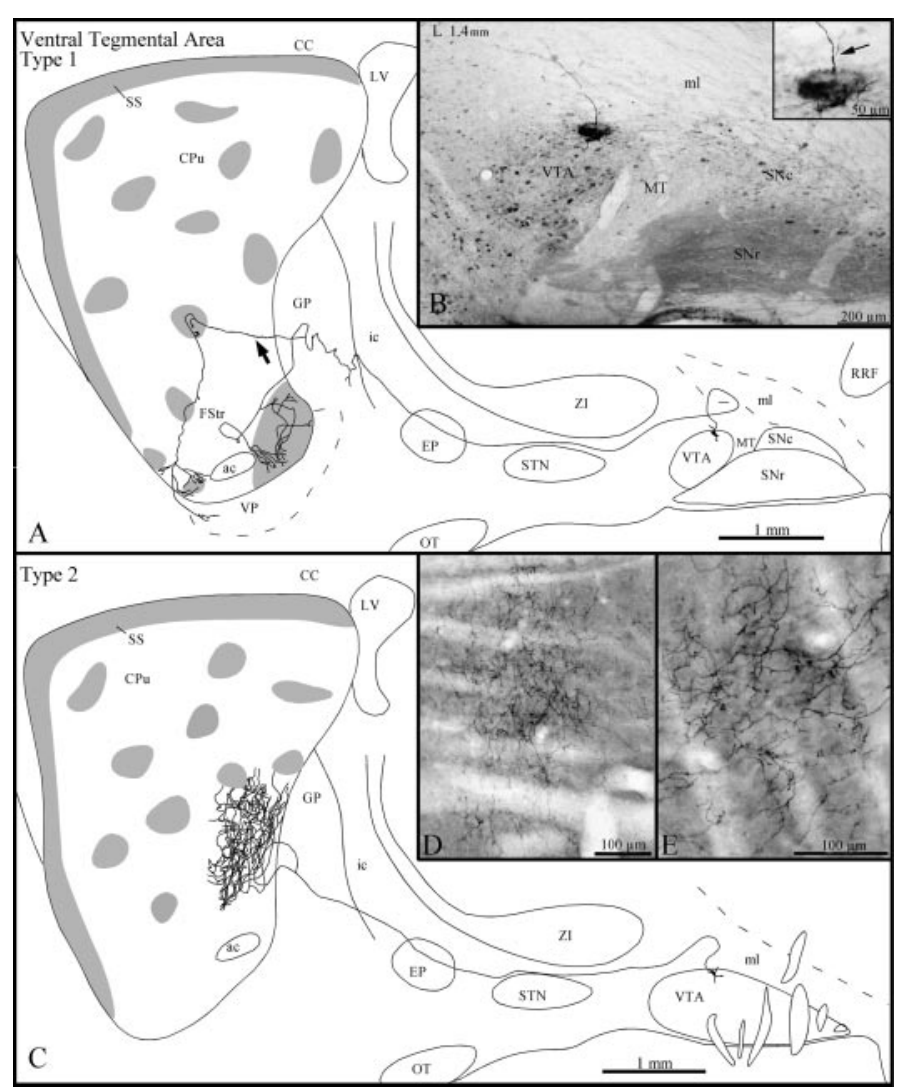

Figure 9. A, Sagittal representation of a type 1 VTA axon, with gray zones representing $\mu \mathrm{R}+$ striosomes and subcallosal streak. The arrow points to the axon collateral that innervates a dorsal striosome before arborizing in the FStr. B, Photomicrograph illustrating the BDA deposit in the dorsal aspect of the VTA. The inset in $B$ is a photographic enlargement of the injection site, and the arrow points to the axon that is drawn in $A$ as it emerges from a primary dendrite. $C$, Sagittal representation of the axonal trajectory and striatal arborization of a type 2 VTA neuron. $D$, Photomicrograph of the dense terminal arborization in the matrix of the axon that is drawn in $C$. $E$, High-power view of some terminal fibers of the same axon at the striatal level. Definitions of abbreviations apply to all figures.

\section{Ventral tegmental area}

On the basis of their pattern of arborization at the striatal level, the axons of these neurons (Fig. $9 B$ ) were subdivided into two types: (1) axons $(n=6)$ that innervated the fundus striati and (2) axons $(n=2)$ that projected to the matrix in the caudoventral aspect of the dorsal striatum.

All type 1 axons exhibited elongated and regularly spaced varicosities along their entire course. They ran above the STN, traversed the EP, and emitted one short and varicose collateral in the caudal aspect of the GP (Fig. 9A). Two type 1 axons emitted also a few terminal boutons in the subincertal nucleus and the EP.

At striatal level, two type 1 axons innervated exclusively and very densely the fundus striati. They branched into a multitude of rather thick fibers exhibiting numerous large varicosities that spread over both $\mu \mathrm{R}+$ and $\mu \mathrm{R}-$ areas of the fundus striati. One of these two axons also provided a few terminal boutons in the ventral portion of the subcallosal streak before arborizing in the fundus striati. The four other type 1 axons arborized less densely in the fundus striati, and their terminal fields, which comprised thin and slightly varicose fibers, were confined to $\mu \mathrm{R}+$ areas (Fig. $9 A)$. At the GP level, these axons emitted one collateral that

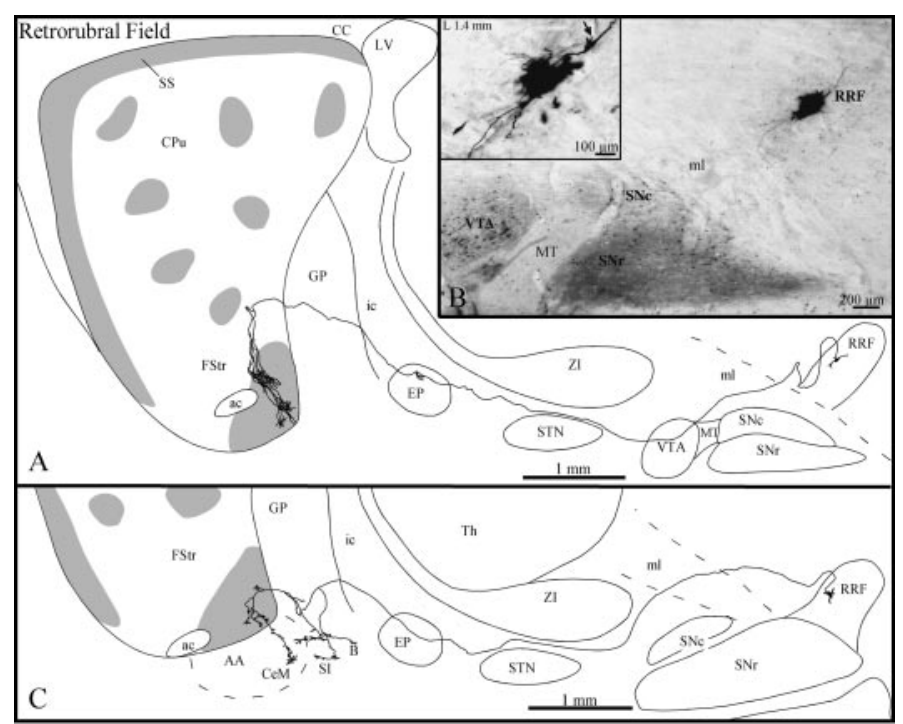

Figure 10. $A, C$, Sagittal view of two axons of the retrorubral field $(R R F)$, with gray zones representing $\mu \mathrm{R}+$ striosomes and subcallosal streak. $B$, Photomicrograph illustrating the BDA deposit in the RRF. The inset in $B$ is a photographic enlargement of the injection site, and the $a r-$ row points to the axon that has been drawn in $A$, as it emerges from the cell body. $B$, Basal nucleus of Meynert; $S S$, substantia innominata. Definitions apply to all figures.

entered the striatum and innervated one or two nearby striosomes located in the ventral sector of the dorsal striatum (Fig. 9A). Then, these collaterals targeted the fundus striati, where they arborized poorly into slightly varicose fibers that spread over both $\mu \mathrm{R}+$ and $\mu \mathrm{R}-$ areas (Fig. 9A). Occasionally, these terminal fibers targeted also the ventral sector of the subcallosal streak or the dorsal aspect of the ventral pallidum (Fig. 9A).

The type 2 axons followed a rather straight course and did not emit collateral en route to the striatum (Fig. 9C). Just before entering the striatum, the axons bifurcated, and the two branches pierced the striatum at the same mediolateral level but slightly separated dorsoventrally (Fig. 9C). At striatal level, each branch broke out into a multitude of thin and slightly varicose fibers that innervated densely a restricted sector of the caudal portion of the striatum (Fig. 9C-E). The terminal field of these axons extended $\sim 700 \mu \mathrm{m}$ along the mediolateral plane and was strictly confined to the matrix (Fig. 9C).

\section{Retrorubral field}

Three axons with parent cell bodies that lay in different sectors of the RRF (Fig. 10B) were entirely reconstructed in the present study. These three axons followed a rather straight course toward the striatum and displayed several elongated varicosities along their trajectory. Two of them coursed medially throughout the VTA before heading toward the striatum and showed numerous large varicosities as they passed through this midbrain structure (Fig. 10A). The three axons ran below the $\mathrm{ZI}$ and traversed the EP, where two of them provided a short and poorly ramified collateral that exhibited a few terminal boutons (Fig. 10A). Two axons traversed the GP without branching and penetrated the fundus striati either directly or after a detour through the ventral third of the dorsal striatum (Fig. 10A). They divided into three or four collaterals that arborized into numerous rather thick and slightly varicose fibers that formed several clusters scattered in the caudal portion of the fundus striati, which was highly immunore- 
active for $\mu \mathrm{R}$ (Fig. 10A). The third axon provided three collaterals in the ventral third of the GP (Fig. 10C). One of them arborized exclusively in the substantia innominata, whereas another coursed toward the central nucleus of the amygdala and provided two small and varicose branches en passant that innervated the substantia innominata and the basal nucleus of Meynert. The third collateral was smaller and innervated only the most ventral aspect of the GP (Fig. 10C). This axon provided several direct collaterals to the ventrocaudal sector of the fundus striati and one collateral that continued toward the central nucleus of the amygdala.

\section{Somatodendritic domain of SNc neurons}

The injection procedure that we used did not lead to a systematic labeling of the entire dendritic arborization of all the neurons with axons that were entirely reconstructed in this study. The present material was thus not entirely suitable for a detailed study of the input-output organization of single SNc neurons. Numerous SNc labeled neurons were nevertheless stained in a Golgi-like fashion, with a beautifully delineated dendritic arbor. These neurons had a medium-sized (mean maximum diameter, 20-30 $\mu \mathrm{m}$ ), ovoid or polygonal perikarya that gave rise to three to six long and smooth dendrites. The axons emerged from the perikarya or a primary dendrite. These thick primary dendrites branched within $20-40 \mu \mathrm{m}$ from the perikarya and gave rise to thinner, poorly branched secondary and tertiary dendrites. The most distal dendrites often displayed spine-like appendages also referred to as "complex endings" or "thin processes" (Yelnik et al., 1987).

The bulk of the dendritic arborization remained within the $\mathrm{SNc}$, except for a few long dendrites that coursed ventrally and invaded the $\mathrm{SNr}$ (Fig. 11). The dorsally radiating dendrites were found to be generally shorter than the ventrally radiating dendrites, some of which could be followed as far down as the cerebral peduncle. Many dorsal tier SNc neurons had dendrites oriented primarily along the mediolateral and rostrocaudal planes, although they also possessed some dorsoventrally oriented dendrites (Fig. 11A). Several ventral tier SNc neurons had dendrites that were oriented mainly along the dorsoventral axis, although they also possessed mediolaterally oriented dendrites (Fig. 11B). Other dorsal and ventral tier SNc neurons had den-

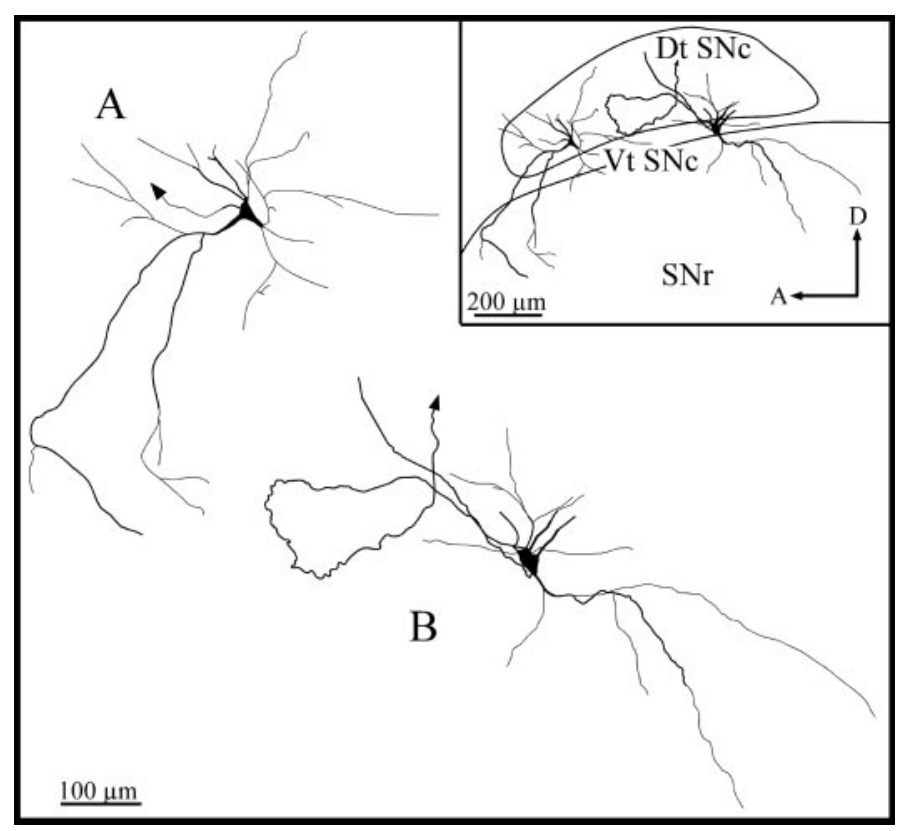

Figure 11. Camera lucida reconstruction of the somatodendritic domain of a dorsal tier SNc neuron $(A)$, the axon of which is depicted in Figure $2 D$, and a ventral tier $\mathrm{SNc}$ neuron $(B)$, the axon of which is illustrated in Figure 6. The arrows indicate the axon. Dt $S N c$, Dorsal tier of SNc; $V t S N c$, ventral tier of SNc. Definitions of abbreviations apply to all figures.

drites that radiated in all directions. The somatodendritic morphology of the SNc neurons reported here is primarily in accord with the results of previous Golgi-staining and intracellularlabeling studies in various species (Juraska et al., 1977; Preston et al., 1981; Tepper et al., 1987; Yelnik et al., 1987). Altogether, these data indicate that the SNc forms a morphological continuum and that the perikaryal shape and dendritic field orientation of each element of this continuum may depend on its location within the structure (Tepper et al., 1987).

\section{DISCUSSION}

The present study has provided the first detailed account of the axonal branching pattern of single neurons located in various

Table 1. Axonal branching patterns of nigrostriatal cells at striatal and extrastriatal levels

\begin{tabular}{|c|c|c|c|c|c|}
\hline \multirow{3}{*}{$\begin{array}{l}\text { Nigral sector, number of labeled } \\
\text { axons }(n) \text {, and cell type }\end{array}$} & \multicolumn{5}{|c|}{ Axonal branching: sites and degree ${ }^{a}$} \\
\hline & \multicolumn{3}{|l|}{$\mathrm{CPu}$} & \multirow[b]{2}{*}{ FStr } & \multirow{2}{*}{$\begin{array}{l}\text { Extrastriatal } \\
\text { structures }\end{array}$} \\
\hline & M & $\mathrm{S}$ & SS & & \\
\hline \multicolumn{6}{|l|}{ Dorsal tier $(n=19)$} \\
\hline Type $1(n=12)$ & $++/+++$ & $-1+$ & $-/+$ & - & $-/+$ \\
\hline Type $2(n=3)$ & $++/++$ & $++/+++$ & $-1+$ & - & $+/++$ \\
\hline Type $3(n=4)$ & - & - & $-/+$ & $++/+++$ & $-/+$ \\
\hline \multicolumn{6}{|l|}{ Ventral tier $(n=23)$} \\
\hline Outside $\operatorname{SNr}(n=12)$ & $-/+$ & + & $-/+$ & - & $-/+$ \\
\hline Within $\operatorname{SNr}(n=7)$ & + & $++/++$ & - & - & $+/++$ \\
\hline \multicolumn{6}{|l|}{ Cell clusters $(n=4)$} \\
\hline 1 & +++ & - & + & - & ++ \\
\hline 2 & + & - & + & - & +++ \\
\hline 3 & - & - & + & - & +++ \\
\hline 4 & - & + & - & - & +++ \\
\hline
\end{tabular}

$\mathrm{CPu}$, Caudate-putamen; FStr, fundus striati; M, striatal matrix compartment; S, striosome; SS, subcallosal streak.

${ }^{a}$ Degrees of axonal branching: - , none; + , weak; ++ , moderate; +++ , high. 
Figure 12. Diagram of the SNc axonal branching patterns at striatal and extrastriatal levels. The continuous arrows indicate that at least $50 \%$ of the neurons targeted the pointed structure, whereas the dotted arrows mean that $<50 \%$ of the neurons innervated the targeted structure. In the schema of the axonal branching patterns of ventral tier cell clusters, numbers 1 and 2 indicate that the axons represented correspond to neurons 1 and 2 in Table 1 . The possibility that these neurons may belong to the $\mathrm{SNr}$ instead of the $\mathrm{SNc}$ is indicated in parentheses. $B S$, Brainstem; $M$, striatal matrix compartment; $S$, striosome. All other abbreviations defined in previous legends.
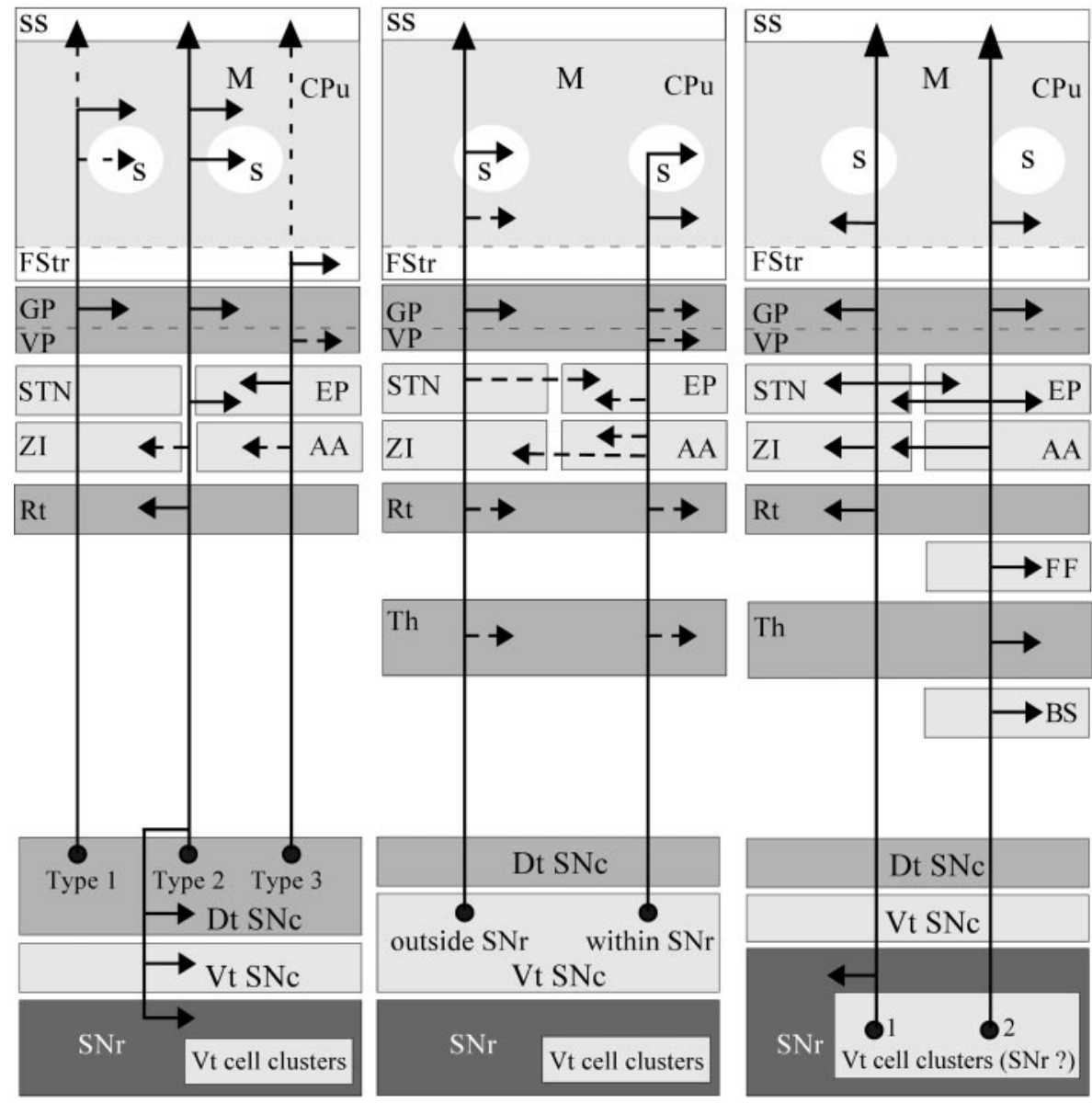

sectors of the SNc/VTA/RRF complex in the rat. It has shed a new light on the relationship between the patterns of termination of nigral axons and the compartmental organization of the striatum and yielded detailed information regarding the branching pattern of midbrain axons at extrastriatal levels.

\section{Compartmental organization of nigrostriatal axons}

This single-axon labeling study supports the striosome/matrix mode of organization of the nigrostriatal system. As predicted from previous data (see introductory remarks), most of the dorsal tier SNc axons traced in the present study (Table 1, type 1) arborize within the matrix of the dorsal striatum. Our data reveal that the pattern and density of arborization of axons that emerge from various sectors of the dorsal tier of the SNc vary markedly. Although some axons innervate exclusively and very densely one specific area in the matrix, others arborize more diffusely in multiple discontinuous matriceal areas scattered dorsoventrally or rostrocaudally. There also exist a few dorsal tier SNc neurons with axons that arborize in both matrix and striosomes (Table 1, type 2). Interestingly, the innervation of the matrix and striosomes by these neurons derives mainly from different axonal branches, as if there were some compartmental selectivity for each branch of these axons.

As could be expected from earlier bulk-injection studies (Gerfen et al., 1987b; Jiménez-Castellanos and Graybiel, 1987; Zahm, 1989; Lynd-Balta and Haber, 1994a,b; Haber and Fudge, 1997), some dorsal tier axons densely innervate the ventral striatum (Table 1, type 3). These axons emerge from neurons closely intermingled with other dorsal tier neurons that project to the dorsal striatum. Axons projecting to the ventral striatum also arise from the VTA. Interestingly, many of these VTA axons send collaterals to specific sets of striosomes located in the ventral part of the dorsal striatum or to the ventral part of the subcallosal streak. The fact that no such collaterals arborize in more dorsally located striosomes suggests that the ventrally located striosomes are more closely related to the ventral or limbic striatum than the dorsal striosomes.

Most of the axons emerging from the ventral tier of the SNc arborize profusely in the striosomal compartment. A few ventral tier axons also arborize in both striatal compartments and, occasionally, in the subcallosal streak (Table 1, Fig. 12). The ventral tier neurons lying outside the $\mathrm{SNr}$ project almost exclusively to dorsally located striosomes and/or dorsal aspects of the subcallosal streak. Furthermore, the axon of such neurons innervates groups of several horizontally aligned striosomes or one or two nearby striosomes plus the distant subcallosal streak. Hence, on the basis of its midbrain inputs, the subcallosal streak can be divided into a ventral "limbic" sector and a dorsal "sensorimotor" sector, a functional organization that allows it to play an important integrative role.

The ventral tier neurons lying within the $\mathrm{SNr}$ also innervate principally dorsal striosomes, but the terminal fields of these neurons often encroach on the surrounding matrix (Table 1, Fig. 12). Interestingly, the ventral tier neurons that form clusters in the deep portion of the $\mathrm{SNr}$ and are considered as displaced $\mathrm{SNc}$ neurons (Van der Kooy, 1979; Guyenet and Crane, 1981; LyndBalta and Haber, 1994a,b,c; Fallon and Loughlin, 1995) innervate 
only weakly, or not at all, the striosomes, but some of them project massively to the matrix and less abundantly to the subcallosal streak (Table 1, Fig. 12). However, the possibility that these ventral tier neurons are not dopaminergic SNc neurons cannot be ruled out. A previous double-retrograde cell-labeling study has revealed the existence of a few nigral cells located at the junction between the SNc and the SNr that projected to both thalamus and striatum (Steindler and Deniau, 1980). However, the chemical identity of these nigral cells, as well as that of the nigral neurons described in the present study, remains to be determined.

\section{Axonal morphology}

Nigral afferents to striosomes and matrix were shown to be morphologically distinct in the rat (Olson et al., 1972; Agnati et al., 1982). Two types of fibers have also been detected in the dorsal striatum in the present study: (1) thin and slightly varicose fibers and (2) very thin fibers displaying many voluminous varicosities. Fibers of the first type are similar to the DA type A fibers, which were detected exclusively in the matrix, whereas fibers of the second type resemble more the DA type B or the non-DA type $\mathrm{C}$ nigrostriatal fibers, which occurred in striosomes and matrix, respectively (Gerfen et al., 1987b). Interestingly, the arborization of some SNc axons comprises collaterals of both types, indicating that such features are independent of striatal compartment and nigral origin. Our data also confirm that fibers terminating within the ventral striatum are thicker and more varicose than those innervating the dorsal striatum (Voorn et al., 1986; Martin et al., 1991; Song and Haber, 2000).

\section{Axonal collateralization}

This study demonstrates that the nigrostriatal pathway is a highly heterogeneous entity composed of several subsystems that display complex patterns of axonal arborization (Fig. 12). In addition to the striatum, this multifaceted system also targets various basal forebrain limbic nuclei, as well as extrastriatal basal ganglia structures. The amygdala and the ventral pallidum, for example, are known to be targeted by SNc and VTA neurons (Fallon and Moore, 1978; Voorn et al., 1986; Klitenick et al., 1992; BrinleyReed and McDonald, 1999). However, our study demonstrates for the first time that these projections consist of collaterals of axons that emerge from the dorsal/ventral tier SNc neurons, or RRF neurons (Fig. 12), and terminate in either the dorsal or the ventral striatum.

We also provide direct evidence for a midbrain projection to the STN and GP, two pivotal basal ganglia nuclei. This finding confirms previous results suggesting the existence of DA nigrosubthalamic and nigropallidal projections in rats (Lindvall and Björklund, 1979; Meibach and Katzman, 1979; Campbell et al., 1985; Hassani et al., 1997), as well as in humans (Cossette et al., 1999; Hedreen, 1999; François et al., 2000; Jan et al., 2000; Prensa et al., 2000). The STN innervation appears to derive from collaterals of neurons lying exclusively in SNc cell clusters deeply embedded in $\mathrm{SNr}$, whereas the GP is innervated by axon collaterals of neurons located in both dorsal and ventral tiers of SNc (Fig. 12). Interestingly, the more these axons arborize in extrastriatal structures the less they branch at the striatal level, and vice versa. In other words, the degree of axonal branching at the striatal level appears to be inversely proportional to the degree of axonal branching at the extrastriatal level.

\section{Local axon collaterals}

Intranigral axon collaterals were seen to arise from two dorsal tier (type 2) and two ventral tier (cluster type) neurons. Hence,
$<10 \%$ of all SNc neurons analyzed here (4 of 42 ) were found to give rise to local axon collaterals. Previous Golgi and intracellular labeling studies failed to demonstrate local collaterals from SNc axons (Juraska et al., 1977; Tepper et al., 1987). These negative findings were used to explain the fact that dopaminergic SNc neurons are less sensitive to the rate-suppressant effect of amphetamine than noradrenergic locus coeruleus neurons, which are well known to issue local collaterals (Groves and Wilson, 1980; Staunton et al., 1980). However, neurons that emit local axon collaterals have been visualized in the SNc of cats (Preston et al., 1981) and primates, including humans (Yelnik et al., 1987). In primates, these local collaterals were reportedly short, few in number (one to three), and poorly arborized (Yelnik et al., 1987). In cats, only nigrostriatal axons with a caudally coursing initial segment (three of eight axons) were found to provide local collaterals, which originated at distances of $200-1000 \mu \mathrm{m}$ from the cell body (Preston et al., 1981). Unfortunately, no detailed description of the terminal arborization of the local axon collaterals was provided for cats or primates.

In the present study, three of the axons that provided local collaterals had a convoluted or caudally oriented initial course, whereas the other one headed rostrally in a rather straightforward manner. The number of local collaterals ranged from two to four, and their degree of branching varied markedly from one to the other. However, the nigral sector covered by these collaterals was rather impressive. For example, the local axon collaterals from dorsal tier neurons arborized in both the dorsal and ventral tiers of the SNc, as well as in the SNr. By comparison, the local collateral network formed by the ventral tier cluster neurons was slightly smaller and confined to the caudal part of the SNr.

Although it arises from a minority of SNc neurons, the intranigral collateral network appears sufficiently well developed to play a major role in the functional organization of the substantia nigra. For example, it may partly control the firing pattern of the various types of SNc/VTA/RRF neurons, which can exert a multifaceted influence on a wide variety of brain structures via their widely distributed axonal arborization. Together with the SNc dendrites, which are synaptically interconnected and able to release DA in situ (Groves and Linder, 1983), this collateral network may also act directly on neurons of the $\mathrm{SNr}$, which is a major output structure of the basal ganglia.

\section{REFERENCES}

Agnati LF, Fuxe K, Zini I, Calza L, Benfenati F, Zoli M, Hökfelt T, Goldstein M (1982) A new approach to quantitate the density and antigen contents of high densities of transmitter-identified terminals. Immunocytochemical studies on different types of tyrosine hydroxylase immunoreactive nerve terminals in nucleus caudatus putamen of the rat. Neurosci Lett 32:253-258.

Berger B, Tassin JP, Blanc G, Moyne MA, Thierry AM (1974) Histochemical confirmation for dopaminergic innervation of the rat cerebral cortex after destruction of the noradrenergic ascending pathways. Brain Res 81:332-337.

Björklund A, Lindvall O (1984) Dopamine systems in the CNS. In: Handbook of chemical neuroanatomy, Classical transmitters in the CNS, Part I (Björklund A, Hökfelt T, eds), pp 55-112. Amsterdam: Elsevier.

Brinley-Reed M, McDonald AJ (1999) Evidence that dopaminergic axons provide a dense innervation of specific neuronal subpopulations in the rat basolateral amygdala. Brain Res 850:127-135.

Bunney BS, Chiodo LA, Grace AA (1991) Midbrain dopaminergic system electrophysiological functioning: a review and new hypothesis. Synapse 9:79-94.

Campbell GA, Eckardt MJ, Weight FF (1985) Dopaminergic mechanisms in subthalamic nucleus of rat: analysis using horseradish peroxidase and microiontophoresis. Brain Res 333:261-270.

Cossette M, Lévesque M, Parent A (1999) Extrastriatal dopaminergic innervation of human basal ganglia. Neurosci Res 34:51-54.

Dahlström A, Fuxe K (1964) Evidence for the existence of monoaminecontaining neurons in the central nervous system. I. Demonstration of 
monoamines in the cell bodies of brain stem neurons. Acta Physiol Scand [Suppl 232] 62:1-55.

Donoghue JP, Herkenham M (1986) Neostriatal projections from individual cortical fields conform to histochemically distinct striatal compartments in the rat. Brain Res 365:397-403.

Fallon JH, Loughlin SE (1985) The substantia nigra. In: The rat central nervous system: a handbook for neuroscientists (Paxinos G, Watson J, eds), pp 353-374. Sydney: Academic.

Fallon JH, Loughlin SE (1987) Monoamine innervation of cerebral cortex and a theory of the role of monoamines in cerebral cortex and basal ganglia. In: Cerebral cortex (Jones EG, Peters A, eds), pp 41-127. New York: Plenum.

Fallon JH, Loughlin SE (1995) Substantia nigra. In: The rat nervous system, Ed 2 (Paxinos G, ed), pp 215-237. San Diego: Academic.

Fallon JH, Moore RY (1978) Catecholamine innervation of the basal forebrain. IV. Topography of the dopamine projection to the basal forebrain and neostriatum. J Comp Neurol 180:545-580.

Fallon JH, Riley JN, Moore RY (1978) Substantia nigra dopamine neurons: Separate populations project to neostriatum and allocortex. Neurosci Lett 7:157-162.

François C, Savy C, Jan C, Tande D, Hirsch EC, Yelnik J (2000) Dopaminergic innervation of the subthalamic nucleus in the normal state, in MPTP-treated monkeys, and in Parkinson's disease patients. J Comp Neurol 425:121-129.

Gauthier J, Parent M, Lévesque M, Parent A (1999) The axonal arborization of single nigrostriatal neurons in rats. Brain Res 834:228-232.

Gerfen CR (1984) The neostriatal mosaic: compartmentalization of corticostriatal input and striatonigral output systems. Nature 311:461-464.

Gerfen CR (1985) The neostriatal mosaic. I. Compartmental organization of projections from the striatum to the substantia nigra in the rat. J Comp Neurol 236:454-476.

Gerfen CR (1992) The neostriatal mosaic: multiple levels of compartmental organization. Trends Neurosci 15:133-139.

Gerfen CR, Wilson CJ (1996) The basal ganglia. In: Handbook of chemical anatomy, integrated systems in the CNS, Part III (Swanson LW, Björkulnd A, Hökfelt T, eds), pp 371-468. Amsterdam: Elsevier.

Gerfen CR, Baimbridge KG, Miller JJ (1985) The neostriatal mosaic: compartmental distribution of calcium-binding protein and parvalbumin in the basal ganglia of the rat and monkey. Proc Natl Acad Sci USA 82:8780-8784.

Gerfen CR, Baimbridge KG, Thibault J (1987a) The neostriatal mosaic: III. Biochemical and developmental dissociation of patch-matrix mesostriatal systems. J Neurosci 7:3935-3944.

Gerfen CR, Herkenham M, Thibault J (1987b) The neostriatal mosaic: II. Patch- and matrix-directed mesostriatal dopaminergic and nondopaminergic systems. J Neurosci 7:3915-3934.

Goldman-Rakic PS (1982) Cytoarchitectonic heterogeneity of the primate neostriatum: subdivision into island and matrix cellular compartments. J Comp Neurol 205:398-413.

Grace AA, Bunney BS (1984a) The control of firing pattern in nigral dopaminergic neurons: single spike firing. J Neurosci 4:2866-2876.

Grace AA, Bunney BS (1984b) The control of firing pattern in nigral dopaminergic neurons: burst firing. J Neurosci 4:2877-2890.

Graybiel AM (1990) Neurotransmitters and neuromodulators in the basal ganglia. Trends Neurosci 13:244-254.

Graybiel AM, Ragsdale CW (1978) Histochemically distinct compartments in the striatum of human, monkey and cat demonstrated by acetylcholinesterase staining. Proc Natl Acad Sci USA 75:5723-5726.

Groves PM, Linder JC (1983) Dendro-dendritic synapses in substantia nigra: description based on analysis of serial sections. Exp Brain Res 49:209-217.

Groves PM, Wilson CJ (1980) Monoaminegic presynaptic axons and dendrites in rat locus coeruleus seen in reconstruction of serial sections. J Comp Neurol 193:853-862.

Guyenet PG, Crane JK (1981) Non-dopaminergic nigrostriatal pathway. Brain Res 213:291-305.

Haber SN, Fudge JL (1997) The primate substantia nigra and VTA: integrative circuitry and function. Crit Rev Neurobiol 11:323-342.

Hassani O-K, François C, Yelnik J, Féger J (1997) Evidence for a dopaminergic innervation of the subthalamic nucleus in the rat. Brain Res 749:88-94.

Hedreen JC (1999) Tyrosine hydroxylase-immunoreactive elements in the human globus pallidus and subthalamic nucleus. J Comp Neurol 409:400-410

Herkenham M, Pert CB (1981) Mosaic distribution of opiate receptors, parafascicular projections and acetylcholinesterase in rat striatum. Nature 291:415-418.

Hsu SM, Raine L, Fanger H (1981) The use of avidin-biotin peroxidase complex $(\mathrm{ABC})$ in immunoperoxidase techniques: a comparison between $\mathrm{ABC}$ and unlabeled antibody (PAP) procedures. J Histochem Cytochem 29:577-580.

Jan C, Francois C, Tande D, Yelnik J, Tremblay L, Agid Y, Hirsch E (2000) Dopaminergic innervation of the pallidum in the normal state, in MPTP-treated monkeys and in parkinsonian patients. Eur J Neurosci $12: 4525-4535$.

Jiménez-Castellanos J, Graybiel AM (1987) Subdivisions of the dopamine-containing A8-A9-A10 complex identified by their differential mesostriatal innervation of striosomes and extrastriosomal matrix. Neuroscience 23:223-242.

Juraska JM, Wilson CJ, Groves PM (1977) The substantia nigra of the rat: a Golgi study. J Comp Neurol 172:565-600.

Klitenick MA, Deutch AY, Churchill L, Kalivas PW (1992) Topography and functional role of dopaminergic projections from the ventral mesencephalic tegmentum to the ventral pallidum. Neuroscience 50:371-386.

Langer LF, Graybiel AM (1989) Distinct nigrostriatal projection systems innervate striosomes and matrix in the primate striatum. Brain Res 498:344-350.

Lindvall O, Björklund A (1979) Dopaminergic innervation of the globus pallidus by collaterals from the nigrostriatal pathway. Brain Res $172: 169-173$.

Lindvall O, Bjorklund A, Divac I (1977) Organization of mesencephalic dopamine neurons projecting to neocortex and septum. Adv Biochem Psychopharmacol 16:39-46.

Lynd-Balta E, Haber SN (1994a) The organization of midbrain projections to the ventral striatum in the primate. Neuroscience 59:609-623.

Lynd-Balta E, Haber SN (1994b) The organization of midbrain projections to the striatum in the primate: sensorimotor-related striatum versus ventral striatum. Neuroscience 59:625-640.

Lynd-Balta E, Haber SN (1994c) Primate striatonigral projections: a comparison of the sensorimotor-related striatum and the ventral striatum. J Comp Neurol 345:562-578.

Martin LJ, Hadfield MG, Dellovade TL, Price DL (1991) The striatal mosaic in primates: patterns of neuropeptide immunoreactivity differentiate the ventral striatum from the dorsal striatum. Neuroscience 43:397-417.

Meibach RC, Katzman R (1979) Catecholaminergic innervation of the subthalamic nucleus: evidence for a rostral continuation of the A9 (substantia nigra) dopaminergic cell group. Brain Res 173:364-368.

Olson L, Seiger A, Fuxe K (1972) Heterogeneity of striatal and limbic dopamine innervation: highly fluorescent islands in developing and adult rats. Brain Res 44:283-288.

Paxinos G, Watson C (1986) The rat brain in stereotaxic coordinates, Ed 2. Sydney: Academic.

Pinault D (1996) A novel single-cell staining procedure performed in vivo under electrophysiological control: morpho-functional features of juxtacellularly labeled thalamic cells and other central neurons with biocytin or neurobiotin. J Neurosci Methods 65:113-136.

Prensa L, Cossette M, Parent A (2000) Dopaminergic innervation of human basal ganglia. J Chem Neuroanat 20:207-213.

Preston RJ, McCrea RA, Chang HT, Kitai ST (1981) Anatomy and physiology of substantia nigra and retrorubral neurons studies by extraand intracellular recording and by horseradish peroxidase labeling. Neuroscience 6:331-344.

Ragsdale CW, Graybiel AM (1981) The fronto-striatal projection in the cat and monkey and its relationship to inhomogeneities established by acetylcholinesterase histochemistry. Brain Res 208:259-266.

Song DD, Haber SN (2000) Striatal responses to partial dopaminergic lesion: evidence for compensatory sprouting. J Neurosci 20:5102-5114.

Staunton DA, Young SJ, Groves PM (1980) The effect of long-term amphetamine administration on the activity of dopaminergic neurons of the substantia nigra. Brain Res 188:107-117.

Steindler DA, Deniau JM (1980) Anatomical evidence for collaterals branching of substantia nigra neurons: a combined horseradish peroxidase and $\left[{ }^{3} \mathrm{H}\right]$ wheat germ agglutinin axonal transport study in the rat. Brain Res 196:228-236.

Tepper JM, Sawyer SF, Groves PM (1987) Electrophysiologically identified nigral dopaminergic neurons intracellularly labeled with HRP: light-microscopic analysis. J Neurosci 7:2794-2806

Van der Kooy D (1979) The organization of thalamic, nigral and raphe cells projecting to the medial vs lateral caudate putamen in rat. A fluorescent retrograde double labeling study. Brain Res 169:381-387.

Voorn P, Jorritsma-Byham B, Van Dijk C, Buijs RM (1986) The dopaminergic innervation of the ventral striatum in the rat: a light- and electron- microscopical study with antibodies against dopamine. J Comp Neurol 251:84-99.

Wang H, Moriwaki A, Wang JB, Uhl GR, Pickel VM (1996) Ultrastructural immunocytochemical localization of $\mu$-opiate receptors and $\mathrm{Leu}^{5}$-enkephalin in the patch compartment of the rat caudate-putamen nucleus. J Comp Neurol 375:659-674.

Yelnik J, François C, Percheron G, Heyner S (1987) Golgi study of the primate substantia nigra. I. Quantitative morphology and typology of nigral neurons. J Comp Neurol 265:455-472.

Zahm DS (1989) Evidence for a morphologically distinct subpopulation of striatipetal axons following injections of WGA-HRP into the ventral tegmental area in the rat. Brain Res 482:145-154. 